Research Paper

\title{
Yin and Yang Regulation of Liver X Receptor $\alpha$ Signaling Control of Cholesterol Metabolism by Poly(ADP-ribose) polymerase 1
}

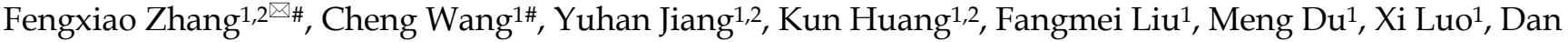 \\ Huang ${ }^{1,2 \bowtie}$ and Kai Huang ${ }^{2^{凶}}$ \\ 1. Department of Cardiovascular Diseases, Union Hospital, Tongji Medical College, Huazhong University of Science and Technology. \\ 2. Clinical Center for Human Genomic Research, Union Hospital, Huazhong University of Science and Technology. \\ \#These authors contributed equally to this work. \\ $\square$ Corresponding authors: Fengxiao Zhang (E-mail: xiaoyou_321@foxmail.com); Dan Huang (E-mail: joy_huangdan@163.com); or Kai Huang \\ (huangkai1@hust.edu.cn). \\ (1) The author(s). This is an open access article distributed under the terms of the Creative Commons Attribution License (https://creativecommons.org/licenses/by/4.0/). \\ See http://ivyspring.com/terms for full terms and conditions.
}

Received: 2020.06.28; Accepted: 2020.08.22; Published: 2020.09.01

\begin{abstract}
Liver $X$ receptor $\alpha(L X R \alpha)$ controls a set of key genes involved in cholesterol metabolism. However, the molecular mechanism of this regulation remains unknown. The regulatory role of poly(ADP-ribose) polymerase 1 (PARPI) in cholesterol metabolism in the liver was examined. Activation of PARPI in the liver suppressed $L X R \alpha$ sensing and prevented upregulation of genes involved in HCD-induced cholesterol disposal. Mechanistically, LXRa was poly(ADP-ribosyl)ated by activated PARPI, which decreased DNA binding capacity of LXRa, thus preventing its recruitment to the target promoter. Intriguingly, we found that unactivated PARPI was indispensable for LXR $\alpha$ transactivation and target expression. Further exploration identified unactivated PARPI as an essential component of the $L X R \alpha-p r o m o t e r$ complex. Taken together, the results indicate that activated PARPI suppresses LXR $\alpha$ activation through poly(ADP-ribosyl)ation, while unactivated PARPI promotes $L X R \alpha$ activation through physical interaction. PARPI is a pivotal regulator of $L X R \alpha$ signaling and cholesterol metabolism in the liver.
\end{abstract}

Key words: PARP1; LXRa; cholesterol metabolism

\section{Introduction}

Nuclear receptors (NRs) comprise a family of ligand-inducible transcription factors involved in metabolism, development and reproduction [1]. The liver $X$ receptors LXRa (NR1H3) and LXR $\beta$ (NR1H2) are oxysterol-activated transcription factors belonging to the steroid/thyroid hormone nuclear receptor superfamily [2-4]. Upon activation, the LXRs form an obligate heterodimer with retinoid $X$ receptor ( $R X R$ ) and subsequently bind to LXR response elements (LXREs) in the target promoter to regulate gene expression [5]. Of these 2 isoforms, LXRa is the master regulator of cholesterol homeostasis through its regulation of genes involved in cholesterol metabolism [6-10]. LXRa signaling has been implicated in the pathogenesis of steatohepatitis and hypercholesterolemia [11]. Efforts to clarify the molecular mechanisms controlling LXRa activity could provide new insights into potential strategies to treat disorders of liver cholesterol metabolism.

Poly(ADP-ribose) polymerase (PARP) 1 accounts for approximately 90 percent of cellular PARP activity [12-15]. Upon activation, it catalyzes the transfer of ADP-ribose units from $\mathrm{NAD}^{+}$onto acceptor proteins [12-15]. This process, namely poly(ADP-ribosyl)ation is an important post-translational modification of proteins, by which PARP1 modifies the properties and functions of acceptor proteins, in addition to being involved in multiple cellular processes, such as DNA repair and replication, transcription, chromatin remodeling etc. [16]. Previous studies have revealed 
that PARP1-mediated poly(ADP-ribosyl)ation can regulate the activities of transcription factors, such as PARP1y, FXRa, ERa and AP-1 [17-20]. Recently, studies have shown that inhibition of PARP1 alleviates hypercholesterolemia and steatohepatitis in mice, implicating a potential role of PARP1 in the pathogenesis of cholesterol disorders [21].

In this study, we reveal a physical and functional coupling between PARP1 and LXRa in the suppression of hepatic cholesterol disposal in HCD-treated mice. PAPR1 exerts two opposite effects on LXRa signaling: activated PARP1 suppresses LXRa transactivity through poly(ADP-ribosyl)ation whereas unactivated PARP1 increases LXRa transactivity through physical interaction.

\section{Methods}

\section{Ethics Statement}

All animal experiments in this study conformed to the National Institutes of Health (NIH) Guide for the Care and Use of Laboratory Animals and were approved by the Ethics Committee of Tongii Medical College, Huazhong University of Science and Technology, under permit number "[2010] S058".

\section{Animal models}

8-10 weeks old male C57BL/6 wildtype mice, 129Sv PARP1 knock out (PARP1\%-, PKO) mice and C57BL/6 LXRa knock out (LXRa $\%$, LKO) mice were obtained from Jackson Laboratory. We crossed mice of 129Sv PKO mice to generate C57BL/ 6 background PKO mice. All mice were housed in specific pathogen free animal house at Huazhong University of Science and Technology. All animal studies were performed in adherence with the Guide for the Care and Use of Laboratory Animals published by the NIH and approved by The Institutional Animal Care and Use Committee of Huazhong University of Science and Technology.

C57BL/ 6 background PKO or WT mice were randomly divided into four groups, depending on diet, which each animal received for 28 days: (1) Chow group $(n=8)$ : animals were fed with standard chow diet (SCD) (8\% rice bran, 51\% maize, 30\% soybean powder, $3 \%$ bone powder, $1.3 \%$ multivitamin and $6.7 \%$ mineral $) ;(2,3 \& 4)$ Animals were fed a high cholesterol diet (HCD) (79.5\% SCD, 3\% cholesterol, $7 \%$ lard, $10 \%$ yolk powder and $0.5 \%$ bile salt). From day 15 for a further 2 weeks they were intraperitoneally injected once a day with either 3-aminobenzamide $(3 \mathrm{AB}, 30 \mathrm{mg} / \mathrm{kg} / \mathrm{d}$, Sigma, $\mathrm{n}=8$, $\mathrm{HCD}+3 \mathrm{AB}$ group), N-(6-oxo-5, 6-dihydrophenanthridin-2-yl)-2-(N, N-dimethylamino)acetamide (PJ34, $10 \mathrm{mg} / \mathrm{kg} /$ day, Sigma, $\mathrm{n}=8$, $\mathrm{HCD}+\mathrm{PJ} 34$ group), or an identical volume of normal saline as a benign vehicle ( $\mathrm{n}=8, \mathrm{HCD}+\mathrm{NS}$ group).

C57-WT or LKO mice (either male or female) were randomly divided into three groups, depending on diet, which each animal received for 28 days, as follows: (1) Chow group: C57-WT or LKO mice fed a SCD; (2) HCD group: C57-WT or LKO mice fed a $\mathrm{HCD}$; (3) HCD+PJ34 group: from day 15, HCD animals were intraperitoneally injected with PJ34 (10 $\mathrm{mg} / \mathrm{kg} /$ day, Sigma) once per day for two weeks.

Eight to ten week old PKO mice (either male or female) were fed a SCD (chow) or HCD for 4 weeks with injection at days 7 and 20 through a tail-vein of a recombinant adenovirus $\left(1 \times 10^{9} \mathrm{pfu}\right)$ encoding wild type human PARP1 gene (HCD+wt-PARP1) or an enzymatically inactive mutant (mut) PARP1 (HCD+mut-PARP1) or vector (HCD+vector). At day 28, all mice were fasted for 16 hours prior to being sacrificed. Transfection efficiency was determined by real time RT-PCR.

Serum samples were drawn from each mouse from the eye socket vein at days $0,14,28$ for serum biochemical analysis. At day 28, all animals were anesthetized with pentobarbital $(50 \mathrm{mg} / \mathrm{kg}$, Sigma, Burlington, MA, USA). The livers were excised and immediately weighed.

\section{Tissue chemistry}

Cholesterol of liver tissue was extracted as described previously study [22]. Plasma HDL, LDL, cholesterol and hepatic cholesterol levels were determined using a commercial kit (Wako Pure Chemical Industries, Osaka, Japan). The bile acid pool size was determined using a Wako total bile acid test (Wako Pure Chemical Industries, Osaka, Japan) following ethanol extraction from a mixed tissue sample comprising liver, gallbladder and the whole small intestine [23].

Mevalonic acid was quantified by liquid chromatography/electrospray ionization tandem mass spectrometry (LC/ESI/MS/MS), using positiveion mode electrospray ionization with a 5500 Q-Trap system (Applied Biosystems, Foster City, CA) as described previously $[24,25]$.

\section{Cell Cultures}

Primary mice hepatocytes were isolated from mice, as previously described [26]. Human hepatoma HepG2 cells (American Type Culture Collection, Manassas, VA, USA) were purchased from the Cell Bank of Type Culture Collection of the Chinese Academy of Sciences. Cells were maintained in 1640 medium (Gibco, Thermo Fisher Scientific, Waltham, Massachusetts, USA), and then incubated with either $3 \mathrm{AB}$ for $24 \mathrm{~h}$, PJ34 for $24 \mathrm{~h}$, hydrogen peroxide (for 30 mins, GW3965 for $24 \mathrm{~h}$ or the appropriate vehicle for 
processing for RNA isolation, Western blotting or EMSA assay. 3AB, PJ34, hydrogen peroxide and GW3965 were obtained from Sigma (Burlington, MA, USA).

\section{DNA Manipulation and Plasmids}

The mammalian expression vectors pCDNA3.1flag-PARP1 encoding wild-type PARP1 was a gift from Dr. Yun Zhang (Qilu Hospital, Shandong University, China). The mut-PARP1 plasmids in which lysine 893 had been replaced with isoleucine (K893I) was generated as described previously using a QuikChange site-directed mutagenesis kit (agilent technologies, Santa Clara, California, USA). Primer: 5'-CAGGCTACATGTTTGGTATAGGGATCTATTTC GCTGAC-3' 5'-TCACGGGCGCTTCAGGCGGG-3'.

The luciferase-reporter plasmid LXRE-TK-LUC (containing three copies of the LXRE consensus sequence) and control plasmid TK-LUC were kindly provided by Dr. David J. Mangelsdorf (University of Texas Southwestern Medical Center, USA) [27]. Wild type and mutant ABCA1 promoter (980 bp) plasmids (PGL3-WT-ABCA1 and PGL3-DR-ABCA1) were kindly provided by Dr. Yoshinari Uehara (Department of Cardiology, Faculty of Medicine, Fukuoka University, Japan) [28] in which a mutation was created at the DR4 site: TGACCGATAGTAA $\mathrm{CCT} \rightarrow$ TGUTGTUGATAGT AUCTAUT.

\section{Electrophoretic Mobility Shift Assay (EMSA) and Supershift Assay}

DNA-protein interactions were detected using a LightShift ${ }^{\mathrm{TM}}$ Chemiluminescent EMSA kit (Pierce, Thermo Fisher Scientific, Waltham, Massachusetts, USA) according to the manufacturer's protocol. The LXRE consensus oligonucleotide sequences were: forward: 5'-CAAGGATGTGTCCCTTCAACTCAATG TGGC-3'; reverse: 5'- GCCACATTGAGTTGAAGGG ACACATCCTTG-3'. Each 5' end was labeled with biotin. In the supershift assay, after incubation of the nuclear extracts with $2 \mu$ g appropriate antibody or IgG at $4^{\circ} \mathrm{C}$ for 60 minutes, biotin-labeled oligonucleotides were added to the reaction and incubated for further EMSA assay.

\section{Chromatin immunoprecipitation (ChIP) and re-ChIP assay}

ChIP assays were performed as previously described [29]. Hepatocytes were sonicated and lysates were immunoprecipitated with appropriate antibody or IgG (negative control). In re-ChIP assays, chromatin was immunoprecipitated with anti-LXRa antibody, eluted with elution buffer supplemented with $10 \mathrm{mM}$ DTT at $37^{\circ} \mathrm{C}$ for $30 \mathrm{~min}$, then diluted 25 fold with dilution buffer $(20 \mathrm{mM}$ Tris- $\mathrm{HCl}(\mathrm{pH} 8.0)$,
$150 \mathrm{mM} \mathrm{NaCl}, 2 \mathrm{mM}$ EDTA, 1\% Triton X-100), and finally re-immunoprecipitated with $\operatorname{IgG}$ or an antibody against PARP1 or PAR (Santa Cruz Biotechnology, Santa Cruz, California, USA). Realtime-PCR was performed using $1 \mu \mathrm{g}$ of template DNA with specific primers for human ABCG1: sense primer: TCAGGATCTGGATGGTGAATG; antisense primer: CACAGTGGGGAAGTAAGGCA. Input chromosomal DNA and ChIP DNA with non-specific IgG were subjected as negative control.

\section{RNA interference and transfection}

Small interfering RNA (siRNAs) was synthesized by RiBoBio Co. Ltd (Guangzhou, Guangdong, China). Transfection of siRNA was performed at a final concentration of $50 \mathrm{nM}$ using Lipofectamine 2000 (Invitrogen, Carlsbad, California, USA). The siRNA sequences are shown in Table 1.

Table 1. Sequences of siRNAs used in this study

\begin{tabular}{ll}
\hline siRNA & Sense Sequence (5'-3') \\
\hline PARP1 & 5'-GGAACAAGGATGAAGTGAA-3' \\
LXRa & 5'-CACAGAGATCCGTCCACAA-3' \\
Unrelated siRNA & 5'-UUCUCCGAACGUGUCACGU-3' \\
\hline
\end{tabular}

\section{Preparation of whole and nuclear extracts}

The methods for the preparation of whole cell and nuclear extracts have been described previously $[18,20]$. Protein concentrations of these extracts were determined using Bradford assay. The cell extracts obtained using this method was stored at $-80^{\circ} \mathrm{C}$ until required for analysis.

\section{Real Time RT-RCR Assay}

Total RNA was isolated using Trizol (Takara Bio, Gunma, Oizumi, Japan) according to the manufacturer's instructions. One $\mu \mathrm{g}$ of total RNA was reverse transcribed using RNA-PCR Kit (Takara Bio, Gunma, Oizumi, Japan) and the resulting cDNA used as PCR template. The mRNA levels were determined by real-time PCR using ABI PRISM 7900 Sequence Detector system (Applied Biosystems, Thermo Fisher Scientific, Waltham, Massachusetts, USA) according to the manufacturer's instructions.

\section{PARP activity assay}

PARP activity was assayed using universal colorimetric PARP assay kit (Trevigen, Helgerman CT, Gaithersburg. USA) according to the manufacturer's instructions. Cell lysates containing 50 $\mu \mathrm{g}$ protein were loaded into 96-well plate coated with histones and biotinylated poly ADP-ribose and incubated for 1 hour, treated with strep-HRP, then read at $450 \mathrm{~nm}$ in a spectrophotometer. 
Western Blot Assay and in vitro proteinprotein interaction assay (far-Western blot)

Western blot analysis was performed as previously described [30]. Antibodies against PARP1 (R\&D, McKinley Place NE Minneapolis, USA), PAR (Trevigen, Helgerman CT, Gaithersburg. USA), histone H1 (Santa Cruz Biotechnology, Santa Cruz, California, USA), $\beta$-actin (Santa Cruz Biotechnology, Santa Cruz, California, USA), GAPDH (Santa Cruz Biotechnology, Santa Cruz, California, USA) or LXRa (Abcam, Cambridge, England) were used as primary antibodies. Specific bands detected using a chemiluminescence assay (ECL detection reagents, Pierce, USA) were recorded onto X-ray film. BioRad Quantity One software (version 4.4) was used for quantification.

Far-western blot assays and AP-PARP1 protein were performed as described previously [17]. Membranes were incubated with $1 \mu \mathrm{g} / \mathrm{ml}$ recombinant PARP1 protein (Trevigen, Helgerman CT, Gaithersburg. USA) or $1 \mu \mathrm{g} / \mathrm{ml}$ AP-PARP1 protein, $1 \mu \mathrm{g} / \mathrm{ml}$ recombinant protein LXRa (Abnova, Taiwan) or $1 \mu \mathrm{g} / \mathrm{ml}$ recombinant $\beta$-actin (Abnova, Taiwan).

\section{Immunoprecipitation assay}

Briefly, $500 \mu \mathrm{g}$ of nuclear extract were incubated with an antibody against PARP1, LXRa, PAR or nonspecific IgG (negative control) at $4^{\circ} \mathrm{C}$ for 1 hour, then on protein- $G$ agarose at $4^{\circ} \mathrm{C}$ for 12 hours. The immunoprecipitants were pelleted by centrifugation at $5000 \times \mathrm{g}$ for 1 -minute then washed 4 times with lysis buffer. The pellets were suspended in SDS gel loading buffer, boiled for 10 mins, and analyzed using Western blot analysis.

\section{Statistical analysis}

Values are shown as means \pm SEM $(n \geq 3)$. The significance of differences was estimated using the independent samples $\mathrm{T}$ test or one-way ANOVA followed by Student-Newmann-Keuls multiple comparison test. $P<0.05$ was considered significant. All statistical analyses were performed using SPSS software (version 11.0, SPSS Inc).

\section{Results}

Inhibition of PARPI activation alleviated HCDinduced hepatic cholesterol accumulation through activation of the $L X R \alpha$ pathway

WT mice were fed a HCD or SCD for 4 weeks, and then hepatic PARP activity was determined. As shown in Figure 1A, HCD mice exhibited reduced PARP activity from day 2, but increased PARP activity at day 28, indicating that HCD feeding affected hepatic PARP activity. Furthermore, nuclear PARP1 from the mouse liver, and poly(ADPribosyl)ation levels of PARP1 were determined. Consistent with the PARP activity, poly(ADPribosyl)ation of PARP1 was suppressed at day 2, but increased at day 28 (Figure 1B). These results indicate that short term HCD feeding suppressed liver PARP1 activation, while chronic HCD feeding promoted.

To investigate whether PARP1 was involved in HCD-induced hepatic cholesterol accumulation, HCD fed mice were treated with 2 structurally unrelated PARP inhibitors, $3 \mathrm{AB}$ or PJ34. Results demonstrated that $3 \mathrm{AB}$ or $\mathrm{PJ} 34$ treatment decreased hepatic cholesterol content (Figure 1C), indicating that inhibition of PARP1 suppressed HCD-induced cholesterol accumulation. Realtime-PCR assays also showed that $3 \mathrm{AB}$ or PJ34 treatment increased the expression of genes involved in cholesterol catabolism and efflux pathway, including CYP7a1, ABCA1, ABCG1, ABCG5, ABCG8, BSEP and ApoE, while there was no significant change in expression of other target genes (Figure 1D). Consistent with this, we found that $3 \mathrm{AB}$ or PJ34 increased the bile acid pool size and the quantity of metabolites of cholesterol catabolism in HCD mice (Figure 1E). Furthermore, HCD-induced hypercholesterolemia was also alleviated after $3 \mathrm{AB}$ or PJ34 treatment (Figures 1F, 1G $\& 1 \mathrm{H})$.

In the liver, LXRa senses the loading of dietary cholesterol and in response, increases the expression of genes involved in cholesterol catabolism and efflux pathway to facilitate cholesterol disposal. Chronic intake of HCD leads to hepatic cholesterol overaccumulation and hypercholesterolemia, reflecting insufficient activation of LXRa signaling [7, 31, 32]. As LXRa is a master regulator controlling cholesterol disposal-related gene expression, we then examined whether the protective effects of PJ34 were mediated through LXRa. To confirm this hypothesis, LKO and C57-WT mice that were fed a HCD were treated with PJ34. As shown in Figures 1I and 1J, PJ34 treatment upregulated cholesterol disposal-related gene expression and suppressed liver cholesterol accumulation in WT mice, but not in LKO mice, indicating that LXRa indeed mediated the effects of PARP1 inhibition. In line with this finding, depletion of LXRa also negated the PJ34-induced increase in ABCA1, ABCG1 and ApoE gene expression in HepG2 cells (Figure 1K).

In this study, we additionally examined the effects of PJ34 and 3AB on liver cholesterol synthesis. The LC-MS/MS assay revealed that neither PJ34 nor $3 \mathrm{AB}$ treatment modified the hepatic content of mevalonic acid (Figure 1L). Moreover, the effect of $3 \mathrm{AB}$ or PJ34 treatment on the expression of genes 
involved in cholesterol synthesis, including HMG- inhibition of PARP1 did not alter hepatic cholesterol CoA reductase and FDFT1 (Figure 1D). Therefore,

synthesis.
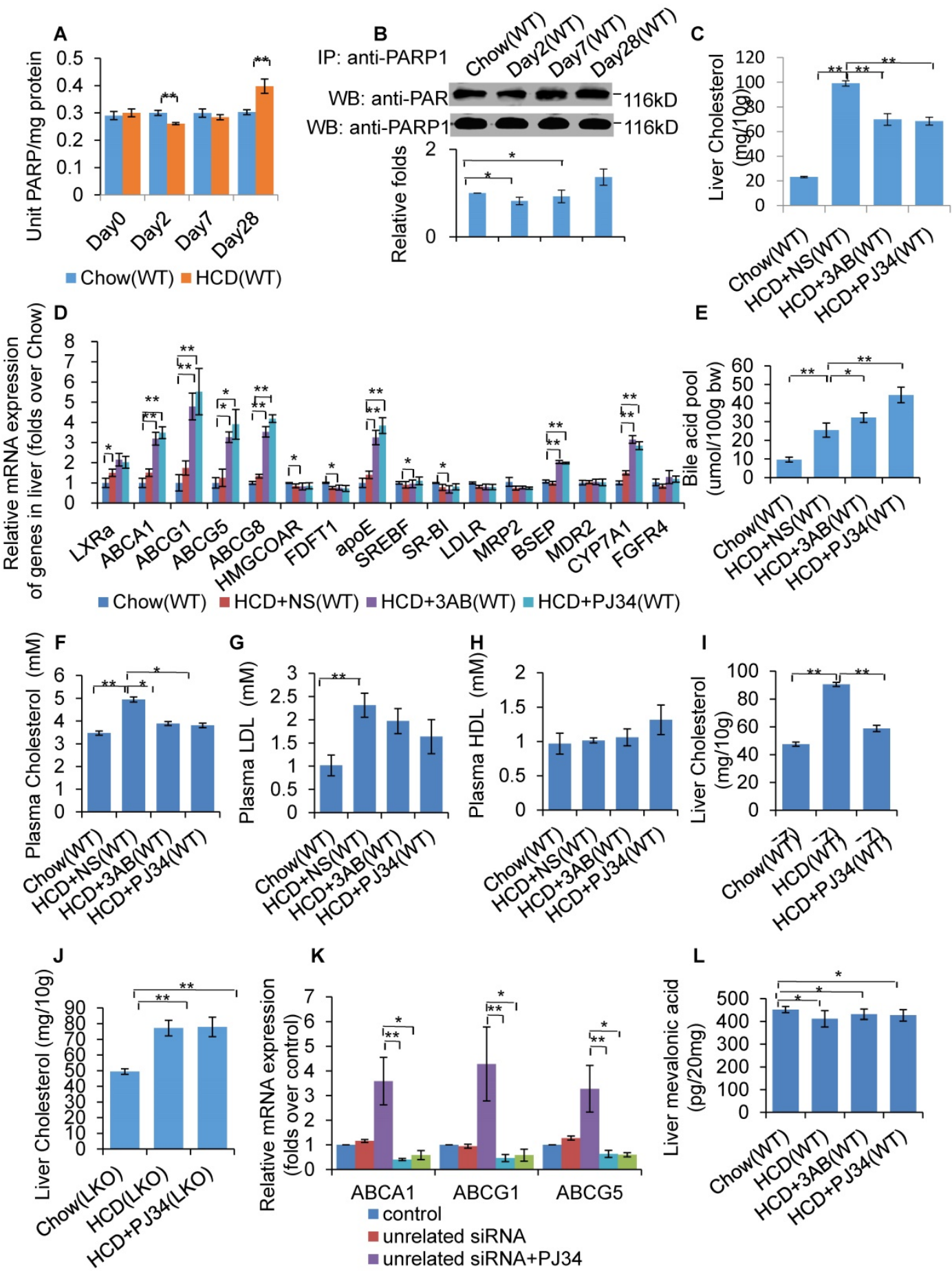

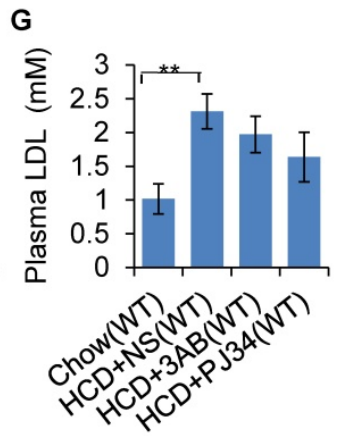

K

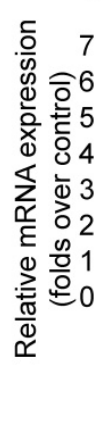

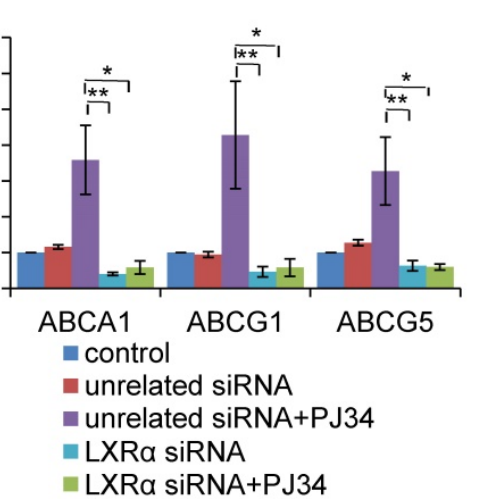
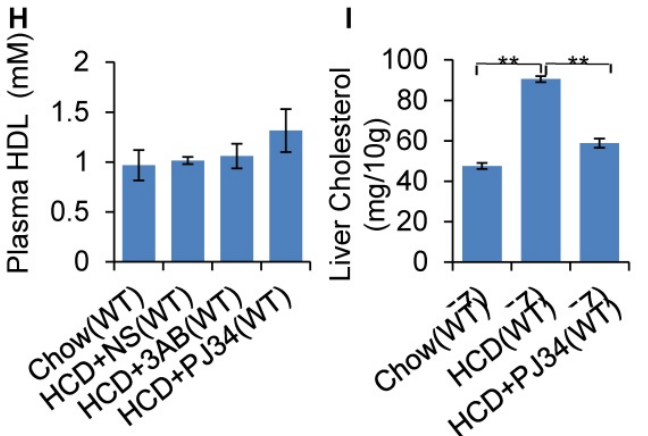

L

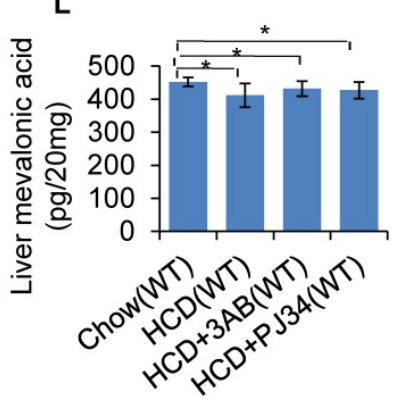

Figure 1. Inhibition of PARPI activation alleviated HCD-induced hepatic cholesterol accumulation through activation of the LXRa pathway. In A-B, WT mice were treated with SCD (Chow group, $n=8$ ) or HCD (HCD group, $n=8)$. Data are expressed as the mean \pm SEM. ** $<0.01$ vs SCD (Chow) group. (A) PARP activity in liver of WT mice. (B) Poly(ADP-ribosyl)ation levels of PARP1 in whole extracts of hepatocytes from WT mice treated with SCD or HCD, determined by IP with PARPI antibody, followed by Western blot analysis using anti-PAR antibody. In C-F and J, WT mice were treated with SCD (Chow group, $\mathrm{n}=8$ ), or $\mathrm{HCD}$ combined with intraperitoneal injection of $3 \mathrm{AB}$ ( $30 \mathrm{mg} / \mathrm{kg} / \mathrm{d}$, $\mathrm{HCD}+3 \mathrm{AB}$ group, $\mathrm{n}=8)$, PJ34 (10 mg/kg/day, HCD+PJ34 group, $\mathrm{n}=8)$ or an identical volume of normal saline (NS, HCD+NS group, $\mathrm{n}=8)$ once per day. (C) Cholesterol concentration in mouse livers. (D) mRNA expression of selected genes in WT mice. (E) Bile acid pool size in WT mice. (F) Plasma cholesterol concentration of WT mice. (G) Plasma LDL concentration of WT mice. $(\mathrm{H})$ Plasma HDL concentration of WT mice. (I) Liver cholesterol concentration in C57 mice which had been fed either a SCD (Chow group, $n=8)$, or HCD $(n=8)$ combined with an intraperitoneal injection of PJ34 (10 mg/kg/day, HCD+PJ34 group, $n=8)$ once per day. (J) Liver cholesterol concentration in LKO mice which had been fed either a SCD (Chow group, $n=8)$, or HCD $(n=8)$ combined with an intraperitoneal injection of PJ34 (10 mg/kg/day, HCD+PJ34 group, $n=8)$ once per day. (K) mRNA expression of selected genes in HepG2 cells which had been pretreated with LXRa siRNA ( $50 \mathrm{nM}, 48 \mathrm{~h}$ ) or unrelated siRNA ( $50 \mathrm{nM}$, $48 \mathrm{~h})$, followed by treatment with PJ34 $(10 \mu \mathrm{M})$ for 24 hours. $(\mathrm{n}=3)(\mathrm{L})$ Mevalonic acid concentration in mouse livers. In $\mathrm{A}$ and $\mathrm{C}$-L, data are expressed as the mean $\pm \mathrm{SEM}$, $* * P<0.01, * P<0.05$. 
A

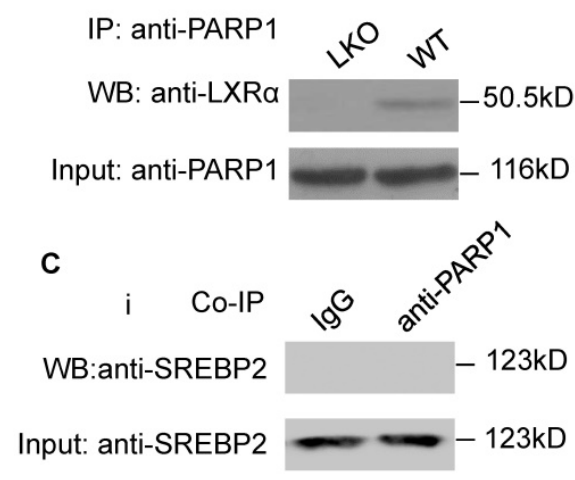

D

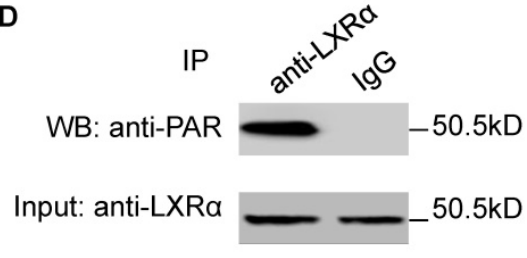

$\mathbf{F}$

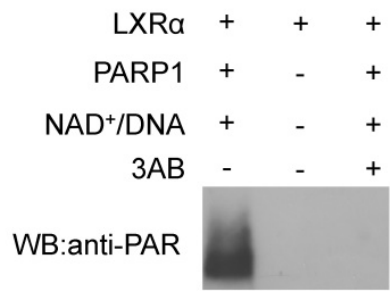

B

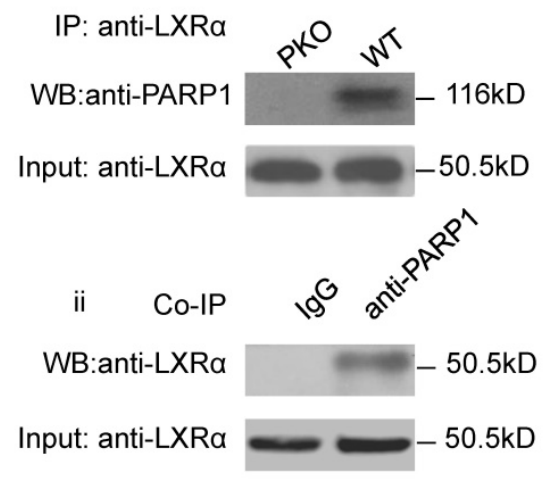

E

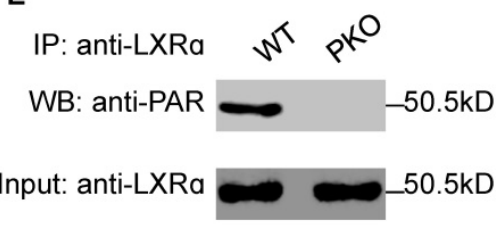

G

IP: anti-LXRa

WB: anti-PAR

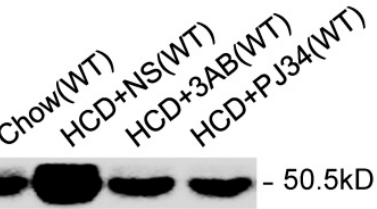

WB: anti-LXRa

Figure 2. LXRa was a substrate of PARP1-mediated poly(ADP-ribosyl)ation reaction in hepatocytes. (A) Co-immunoprecipitation (Co-IP) of PARPI bound proteins from the hepatocytes of C57-WT or LKO mice, followed by Western blot analysis using an anti-LXRa antibody $(\mathrm{n}=3)$. (B) Co-immunoprecipitation (Co-IP) of PARPI-bound proteins from hepatocytes of WT or PKO mice, followed by Western blot analysis using an anti-LXRa antibody ( $n=3$ ). (C) Co-immunoprecipitation (Co-IP) of PARPI-bound proteins from HepG2 cells, followed by Western blot analysis using either (i) SREBP2 or (ii) LXRa antibodies. Non-specific lgG served as negative control $(n=3)$. (D) Poly(ADP-ribosyl)ation levels of LXRa in whole extracts of HepG2 cells determined by IP with LXRa, followed by Western blot analysis using anti-PAR antibody. Non-specific IgG served as negative control $(n=3)$. (E) Poly(ADP-ribosyl)ation levels of $L X R \alpha$ in whole extracts of hepatocytes from WT and PKO mice determined by IP with LXRa, followed by Western blot analysis using anti-PAR antibody. Western-blotting with anti-LXRa antibody served as the loading control $(n=3)$. (F) Recombinant $L X R \alpha$ proteins incubated with PBS vehicle, PARPI/NAD + active DNA or PARPI/NAD+/active DNA/3AB. Western blot analysis was used to detect LXRa poly(ADP-ribosyl)ation levels ( $n=3$ ). (G) LXRa poly(ADP-ribosyl)ation levels in the livers of WT mice determined by IP followed by Western blot analysis using anti-PAR antibody. WT mice were fed SCD $(n=8)$, or HCD combined with NS $(n=8), 3 A B(n=8)$ or PJ34 $(n=8)$.

\section{LXR $\alpha$ was a substrate of PARP 1-mediated poly(ADP-ribosyl)ation reaction in hepatocytes}

As we had established that LXR $\alpha$ mediates the effects of PARP1 inhibition on hepatic cholesterol metabolism, we wished to explore the interaction of PARP1 with LXRa. Nuclear extracts from hepatocytes of C57-WT or LKO mice were assayed by coimmunoprecipitation (co-IP) with an anti-PARP1 antibody. As shown in Figure 2A, nuclear LXRa could be precipitated by the anti-PARP1 antibody from C57-WT hepatocytes, but not from LKO hepatocytes, indicating that a physical interaction occurs between LXRa and PARP1. Concomitant with this conclusion, nuclear PARP1 could also be precipitated by anti-LXRa antibody from WT hepatocytes, but not from PKO hepatocytes (Figure 2B). In this study, we also examined whether PARP1 could interact with
SREBP2, another cholesterol metabolism-related transcription factor. However, in contrast to LXRa, SREBP2 could not be precipitated by the anti-PARP1 antibody (Figure 2C).

We next explored whether LXRa could be poly(ADP-ribosyl)ated by PARP1. Nuclear LXRa was precipitated by anti-LXRa antibody then analyzed by Western blotting with an anti-PAR antibody (Figure 2D). As shown in Figure 2E, poly(ADP-ribosyl)ation of LXRa was detected in nuclear extracts of WT hepatocytes, but not of PKO hepatocytes, indicating that LXRa could be poly(ADP-ribosyl)ated by PARP1. This finding was further confirmed by the observation that incubation of LXRa with recombinant PARP1 and $\mathrm{NAD}^{+} /$nicked DNA resulted in poly(ADPribosyl)ation of LXRa in a cell-free system (Figure 2F). Furthermore, HCD mice displayed increased poly(ADP-ribosyl)ation of LXRa (Figure 2G). All these suggested that chronic HCD feeding promotes 
poly(ADP-ribosyl)ation of liver LXRa.

\section{Poly(ADP-ribosyl)ation prevented LXR $\alpha$ transactivation and target expression}

To evaluate the effect of PARP1 inhibition on LXRa transactivation, luciferase reporters driven by wild-type (wt) and DR4 mutant (direct repeat with four intervening nucleotides in LXRE) promoters of the human $A B C A 1$ gene were transfected into HepG2 cells, and their respective luciferase activity examined thereafter. As shown in Figure 3A, treatment with PJ34, 3AB or the LXRa agonist GW3965 increased the luciferase activity driven by the wt-promoter, but not by the DR4 mut-promoter. To further confirm this finding, the effects of PARP inhibitors on luciferase reporter driven by $3 \times \mathrm{LXRE}$ were evaluated. As shown in Figure 3B, both PJ34 and $3 \mathrm{AB}$ treatment of cells resulted in increased luciferase activity driven by $3 \times L X R E$, implicating that the inhibition of PARP1 promoted LXRa transactivation. Concomitantly, knockdown of LXRa abolished PJ34-induced 3xLXRE activation (Figure 3C).

Furthermore, cells were challenged with hydrogen peroxide $\left(\mathrm{H}_{2} \mathrm{O}_{2}\right)$, a well-established activator of PARP1 [32]. Treatment with $\mathrm{H}_{2} \mathrm{O}_{2}$ not only increased the poly(ADP-ribosyl)ation of LXRa, but also suppressed 3xLXRE-driven luciferase activity, indicating that poly(ADP-ribosyl)ation suppressed LXRa transactivation (Figures 3D \& 3E). In support of this finding, administration of PJ34 significantly reversed $\mathrm{H}_{2} \mathrm{O}_{2}$-induced inhibition of 3xLXRE-driven luciferase activity (Figure 3E). besides, EMSA assay uncovered that, incubation of nuclear extracts from HepG2 cells with $\mathrm{NAD}^{+} /$nicked DNA, which promoted endogenous LXRa poly(ADP-ribosyl)ation, decreased the LXRa-LXRE complex formation (Figure 3F). Consistently, incubation of LXRa with recombinant human PARP1 and $\mathrm{NAD}^{+} /$nicked DNA effectively suppressed LXRa-LXRE complex formation in a cell free system (Figure 3G). In line with this finding, treatment with $\mathrm{H}_{2} \mathrm{O}_{2}$ reduced LXRa-LXRE complex formation in a dosage-dependent manner (Figure $3 \mathrm{H}$ ). These results indicate that poly(ADP-ribosyl)ation reduced the DNA binding capacity of LXRa.

We then explored whether poly(ADP-ribosyl)ation decreased the recruitment of LXRa to the target promoter. ChIP assay showed that $\mathrm{H}_{2} \mathrm{O}_{2}$ treatment suppressed recruitment of LXRa to the ABCG1 promoter, and this inhibition was reversed by administration of PJ34 (Figure 3I). Consistent with this, $\mathrm{H}_{2} \mathrm{O}_{2}$ treatment also inhibited ABCA1, ABCG1 and ABCG5 expression (Figures 3J \& 3K). Taken together, these results demonstrate that poly(ADP-ribosyl)ation can suppress LXRa binding to its target promoter, leading to decreased expression of its target genes.

\section{PARP 1 is required for $L X R \alpha$ transactivation and target expression}

As PARP1 suppresses LXRa transactivation through poly(ADP-ribosyl)ation, it was postulated that deletion of PARP1 will also lead to an increase in LXRa transactivity. However, knockdown of PARP1 dramatically suppressed the expression of LXRa target genes (Figure 4A). Concomitantly, PARP1 knockout inhibited expression of ABCG1 and ABCG5 (Figure 4B). These results clearly suggest that PARP1 is required for LXRa target expression. In support of this finding, forced expression of the human wild type PARP1 (wt-PARP1) restored ABCG1 and ABCG5 expression in PKO cells (Figure 4B).

We then examined the effects of PARP1 deficiency on the recruitment of LXRa to its target promoter. ChIP assays revealed that, PARP1 knockout decreased binding of LXRa to the ABCG1 promoter. Since over-expression of wt-PARP1 restored this binding (Figure 4C), these data established that PARP1 was a prerequisite for LXRa binding to the target promoter. Besides, EMSA assays proved that $\mathrm{PKO}$ hepatocytes manifested decreased binding of the LXRa probe compared to WT hepatocytes (Figure 4D). Consistently, 3xLXRE driven luciferase activity was weaker in PKO cells than it was in WT cells (Figure 4E). Taken together, these data illustrate that PARP1 is required for binding of LXRa to LXRE in the target promoter and transactivation.

Now that it has been established that PARP1 is required for LXRa transactivation, we thus suspected that deficiency of PARP1 could aggravate HCDinduced cholesterol accumulation. As shown in Figure 4F, PKO mice displayed aggravated hepatic cholesterol accumulation, compared to their WT counterparts. Consistent with this, the expression of LXRa targets were significantly lower in PKO mice (Figure 4G). Intriguingly, despite PKO mice manifesting increased hepatic cholesterol accumulation, their hypercholesterolemia was ameliorated (Figure 4H-J), implying that the regulation of whole body cholesterol homeostasis by PARP1 is considerably more complicated than the current model.

In this study, the contrary effects of PARP1 deficiency and pharmacological inhibitors prompted us to speculate whether the protective effects of PJ34 and $3 \mathrm{AB}$ were mediated through PARP1. To confirm this, HCD fed PKO mice were treated with $3 \mathrm{AB}$ or PJ34. As shown in Figures $4 \mathrm{~K}$ and $4 \mathrm{~L}$, the regulating effects of PJ34 and $3 \mathrm{AB}$ on HCD-induced hepatic cholesterol accumulation and LXRa target expression 
were abrogated. Consistently, PARP1 knockdown abolished PJ34-indcued ABCG1, ABCG5 and ApoE expression in HepG2 cells (Figure 4M). Taken together, the effects of $3 \mathrm{AB}$ or $\mathrm{PJ} 34$ on hepatic cholesterol accumulation and the LXRa pathway are mediated by PARP1.
A

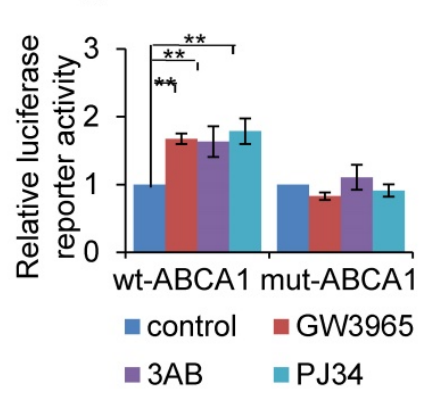

D

IP: anti-LXRa WB: anti-PAR WB: anti-LXRa

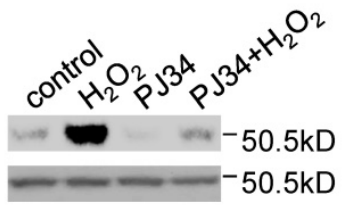

G

H
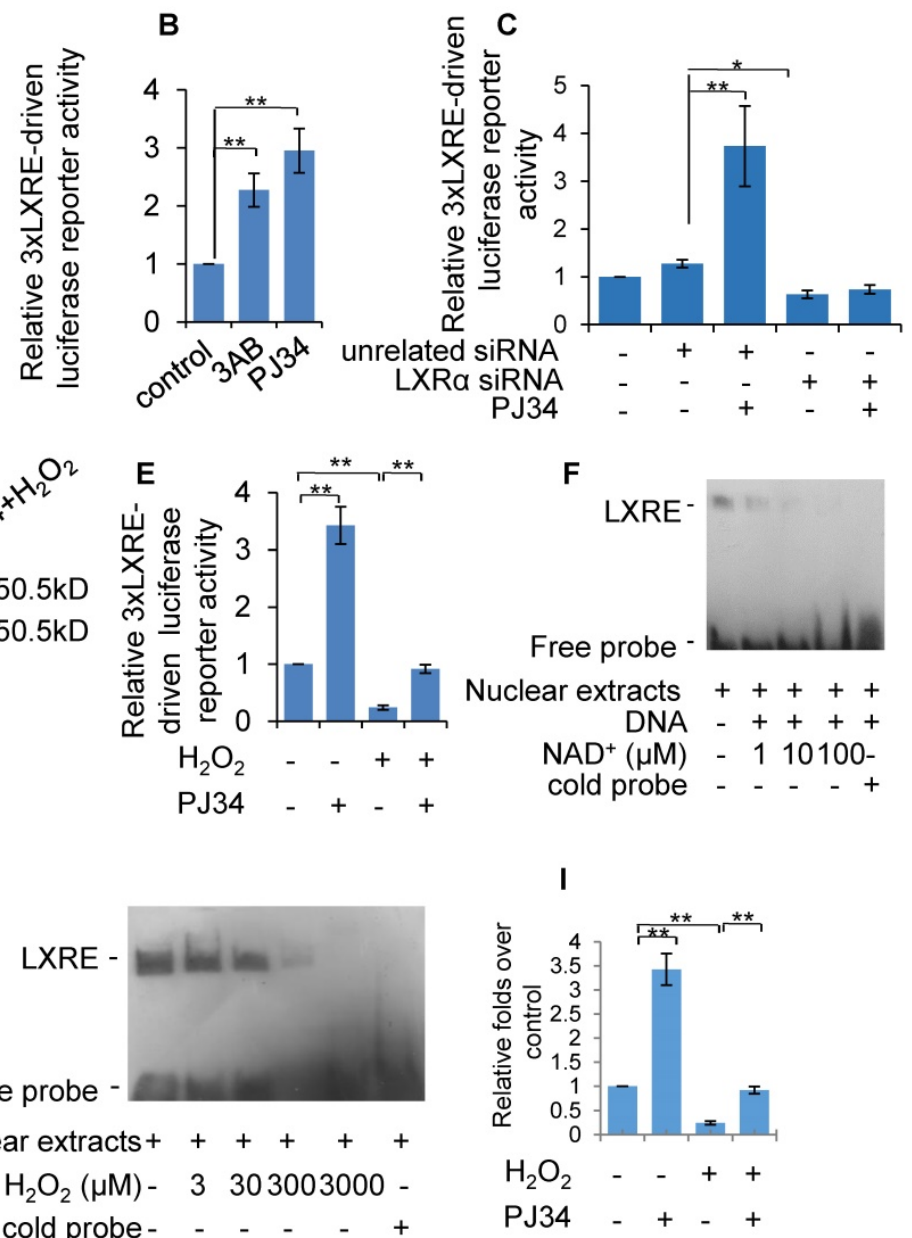
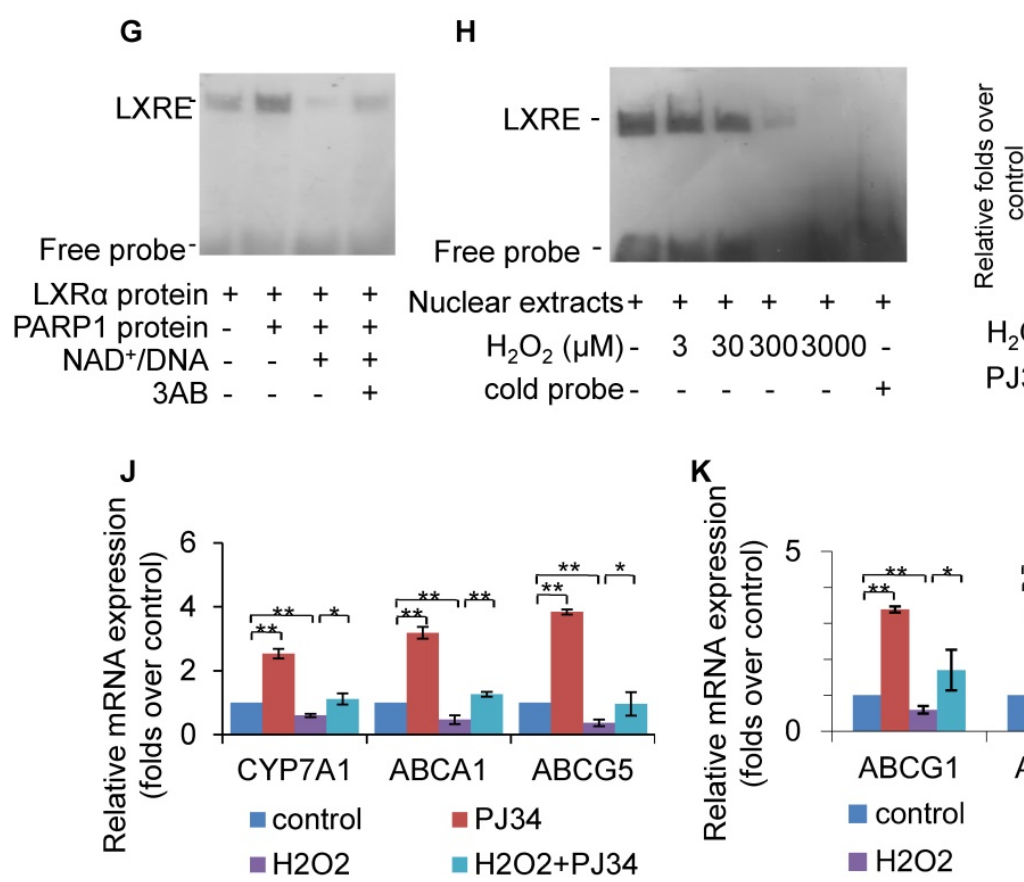

Figure 3. Poly(ADP-ribosyl)ation prevented LXRa transactivation and target expression. (A) Relative luciferase activity of HepG2 cells transfected with $A B C A 1$ promoter-driven luciferase reporter. Wild-type human ABCAl promoter (WT-ABCAl) and mutant (DR-ABCAl) were co-transfected with pRL-SV40 plasmid. Cells were

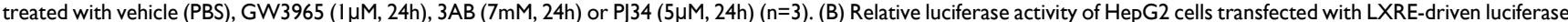
reporter. Cells were treated with vehicle (PBS), 3AB $(7 \mathrm{mM}, 24 \mathrm{~h})$ or PJ34 $(5 \mu \mathrm{M}, 24 \mathrm{~h})(\mathrm{n}=3)$. (C) Relative luciferase activity of HepG2 cells transfected with LXRE-driven luciferase reporter. Cells were pretreated with LXRa siRNA $(50 \mathrm{nM}, 48 \mathrm{~h})$ or unrelated siRNA $(50 \mathrm{nM}, 48 \mathrm{~h})$, followed by treatment with PJ34 (10 $\mu$ M) for 24 hours ( $\mathrm{n}=3)$. (D) Poly(ADP-ribosyl)ation levels of LXRa in whole extracts of HepG2 cells were quantified using IP with LXRa, followed by Western blot analysis using anti-PAR antibody. Western-blotting with anti-LXRa antibody served as the loading control. Cells were treated with vehicle ( $\mathrm{PBS}$ ) or $\mathrm{H}_{2} \mathrm{O}_{2}(0.3 \mathrm{mM}, 0.5 \mathrm{~h})$ in the absence or presence of $\mathrm{PI} 34$ ( 10 $\mu M, 24 h)(n=3)$. (E) Relative luciferase activity of HepG2 cells transfected with $L X R E$-driven luciferase reporter. Cells were treated with vehicle (PBS) or $\mathrm{H}_{2} \mathrm{O}_{2}(0.3 \mathrm{mM}, 0.5 \mathrm{~h})$ in the absence or presence of PJ34 $(10 \mu M, 24 h)(n=3)$. (F) Nuclear extracts from non-treated HepG2 cells were incubated with active DNA and NAD+ $(1,10,100 \mu M)$, then analyzed using an EMSA assay $(n=3)$. (G) EMSA assay of recombinant proteins in cell free system using $L X R E$ as probe. Recombinant $L X R a$ protein was incubated with recombinant PARPI protein, PARPI protein/NAD+/active DNA or PARP1 protein/NAD+/active DNA/3AB ( $n=3)$. (H) EMSA assay of $L X R \alpha-L X R E$ complex formation in nuclear extracts from HepG2 cells treated with vehicle (PBS) or $\mathrm{H}_{2} \mathrm{O}_{2}(3,30,300,3000 \mu M, 0.5 \mathrm{~h})(\mathrm{n}=3)$. (I) ChIP-PCR assay using anti-LXRa antibody for amplification of $A B C G 1$ promoters in HepG2 cells following treatment with vehicle (PBS) or $\mathrm{H}_{2} \mathrm{O}_{2}(0.3 \mathrm{mM}, 0.5 \mathrm{~h})$ in the absence or presence of $\mathrm{PJ} 34$ (10 $\left.\mu M, 24 \mathrm{~h}\right)(\mathrm{n}=3)$. (J) mRNA expression of selected genes in primary hepatocytes from WT mice. Cells were treated with vehicle (PBS) or $\mathrm{H}_{2} \mathrm{O}_{2}(0.3 \mathrm{mM}, 0.5 \mathrm{~h})$ in the absence or presence of PJ34 (10 $\left.\mu M, 24 \mathrm{~h}\right)(\mathrm{n}=3)$. (K) mRNA expression of selected genes in HepG2 cells treated with vehicle (PBS) or $\mathrm{H}_{2} \mathrm{O}_{2}(0.3 \mathrm{mM}, 0.5 \mathrm{~h})$ in the absence or presence of PJ34 (10 $\mu$ M, $\left.24 \mathrm{~h}\right)$ ( $\left.n=3\right)$. In $A-C$, E and I-K, data are expressed as mean \pm SEM, ${ }^{*} \mathrm{P}<0.01,{ }^{*} \mathrm{P}<0.05$ 

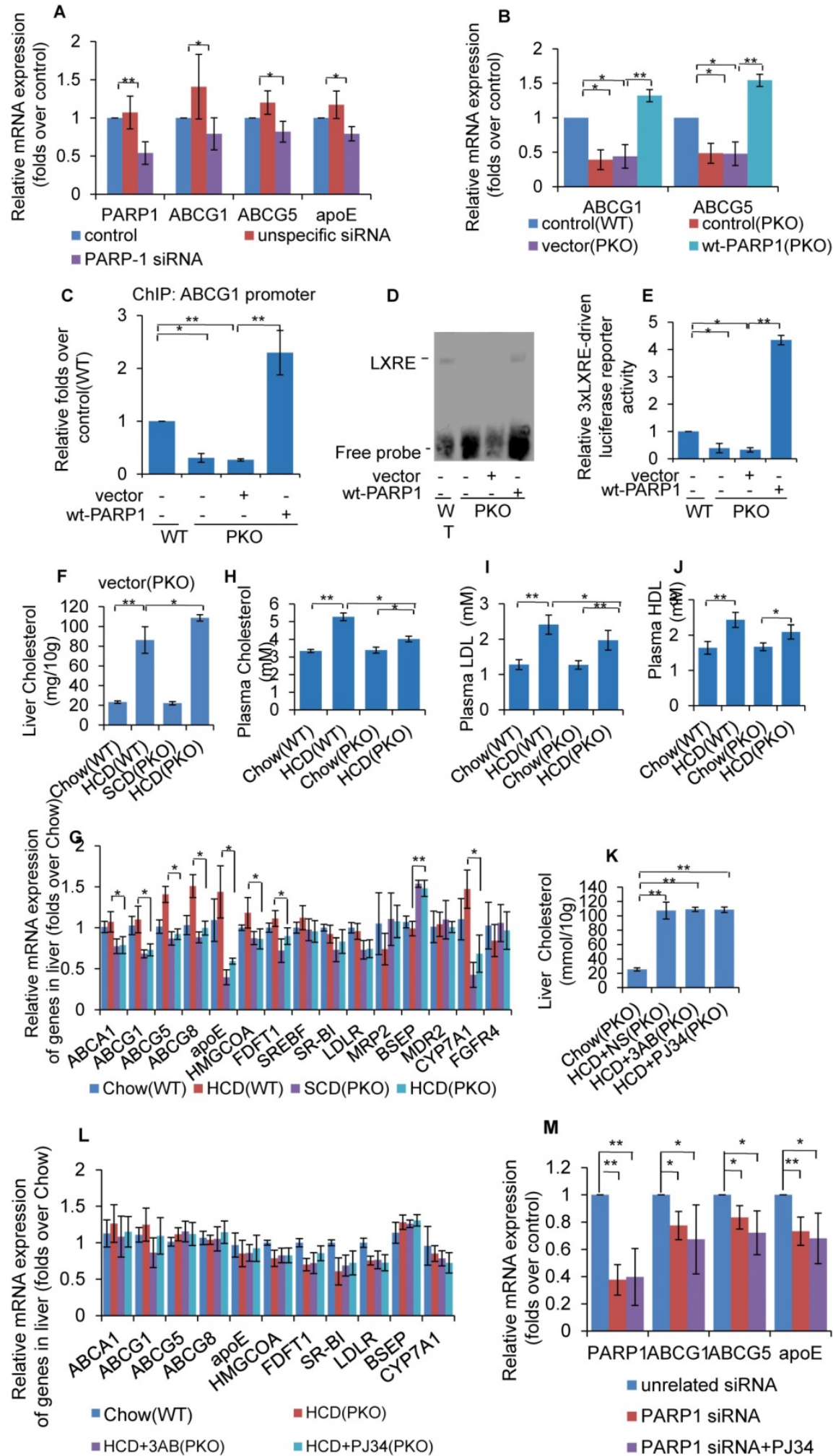

Figure 4. Un-poly(ADP-ribosyl)ated PARP1 is required for LXR $\alpha$ transactivation and target expression. (A) mRNA expression of selected genes in HepG2 cells treated with PARP1 siRNA $(50 \mathrm{nM}, 48 \mathrm{~h})$ or unrelated siRNA $(50 \mathrm{nM}, 48 \mathrm{~h})(\mathrm{n}=3)$. (B) mRNA expression of selected genes in hepatocytes from WT or PKO mice transfected with either empty (PCDNA3.1) or full-length (wt-PARPI) vector for 48 hours $(n=3)$. (C) ChIP-PCR assay using anti-LXRa antibody for amplification of ABCG1 promoters in hepatocytes from WT or PKO mice. Cells were transfected with empty or full-length vector (wt-PARPI) ( $n=3$ ). (D) EMSA assay of $L X R \alpha-L X R E$ complex formation in hepatocytes from WT or PKO mice transfected with empty (PCDNA3.1) or full-length (wt-PARPI) vector for 48 hours $(n=3)$. (E) Relative LXRE-driven luciferase activity in hepatocytes from WT or PKO mice. Cells were transfected with empty or full-length vector (wt-PARPI) $(n=3)$. In F-G, WT or PKO mice were fed a SCD (Chow group, $n=8)$ or HCD ( $=8)$. ( $F$ ) Cholesterol concentration in the livers of WT and PKO mice. (G) mRNA expression of selected genes in the livers of WT and PKO mice assessed by real time RT-PCR assay. In $\mathrm{H}-\mathrm{I}$, PKO mice were fed a SCD Chow group, $\mathrm{n}=8)$, or $\mathrm{HCD}$ combined with intraperitoneal injection with $\mathrm{AB}(30 \mathrm{mg} / \mathrm{kg} / \mathrm{d}, \mathrm{HCD}+3 \mathrm{AB}$ group, $\mathrm{n}=5), \mathrm{PJ} 34(10 \mathrm{mg} / \mathrm{kg} / \mathrm{day}, \mathrm{HCD}+\mathrm{PJ} 34 \mathrm{group}$, $n=5$ ) or an identical volume of normal saline (NS, HCD+NS group, $n=5)$, once per day. (H) Plasma cholesterol concentration in WT or PKO mice. (I) Plasma LDL concentration in WT or PKO mice. (J) Plasma HDL concentration in WT or PKO mice. (K) Cholesterol concentration in the livers of PKO mice. (L) mRNA expression of selected genes in PKO mice. (M) mRNA expression of selected genes in HepG2 cells treated with PARP1 siRNA ( $50 \mathrm{nM}, 48 \mathrm{~h}$ ) or unrelated siRNA (50 nM, $48 \mathrm{~h})$ in the absence or presence of PJ34 (10 $\mu M, 24 h)(n=3)$. In $A-C$ and $E-M$, data repesent mean $\pm S E M, * P<0.05, * * P<0.01$. 
A

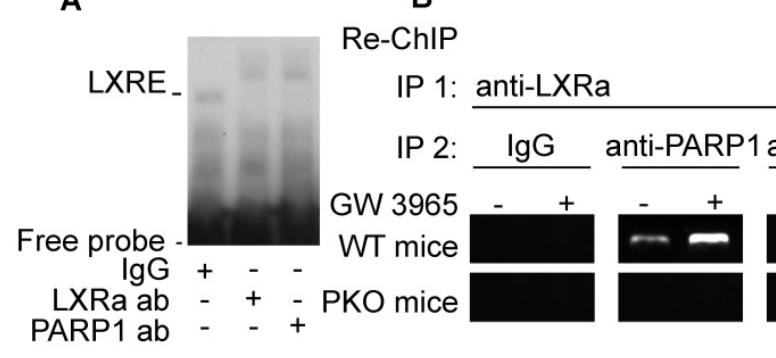

\section{B}

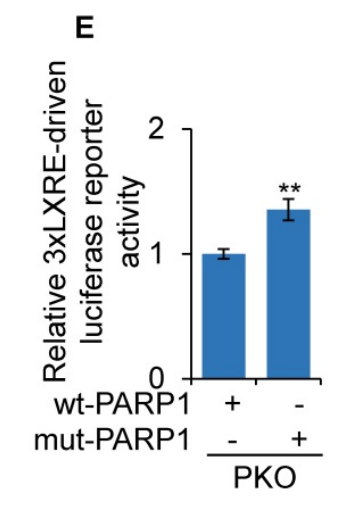

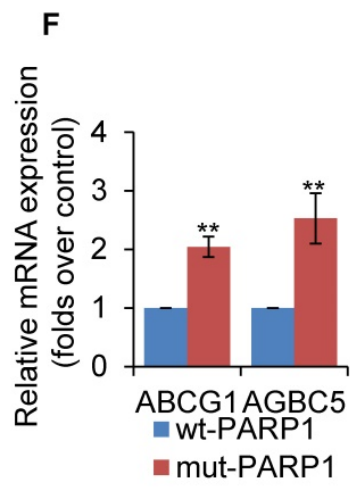

C

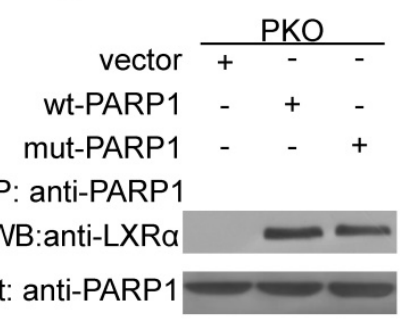

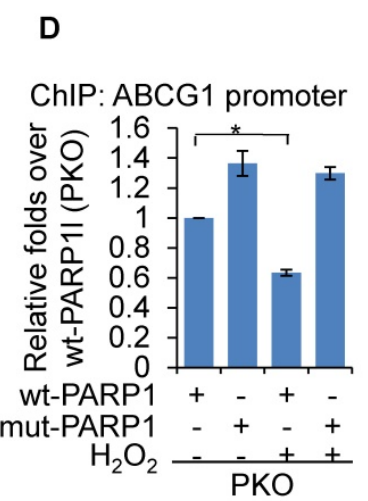
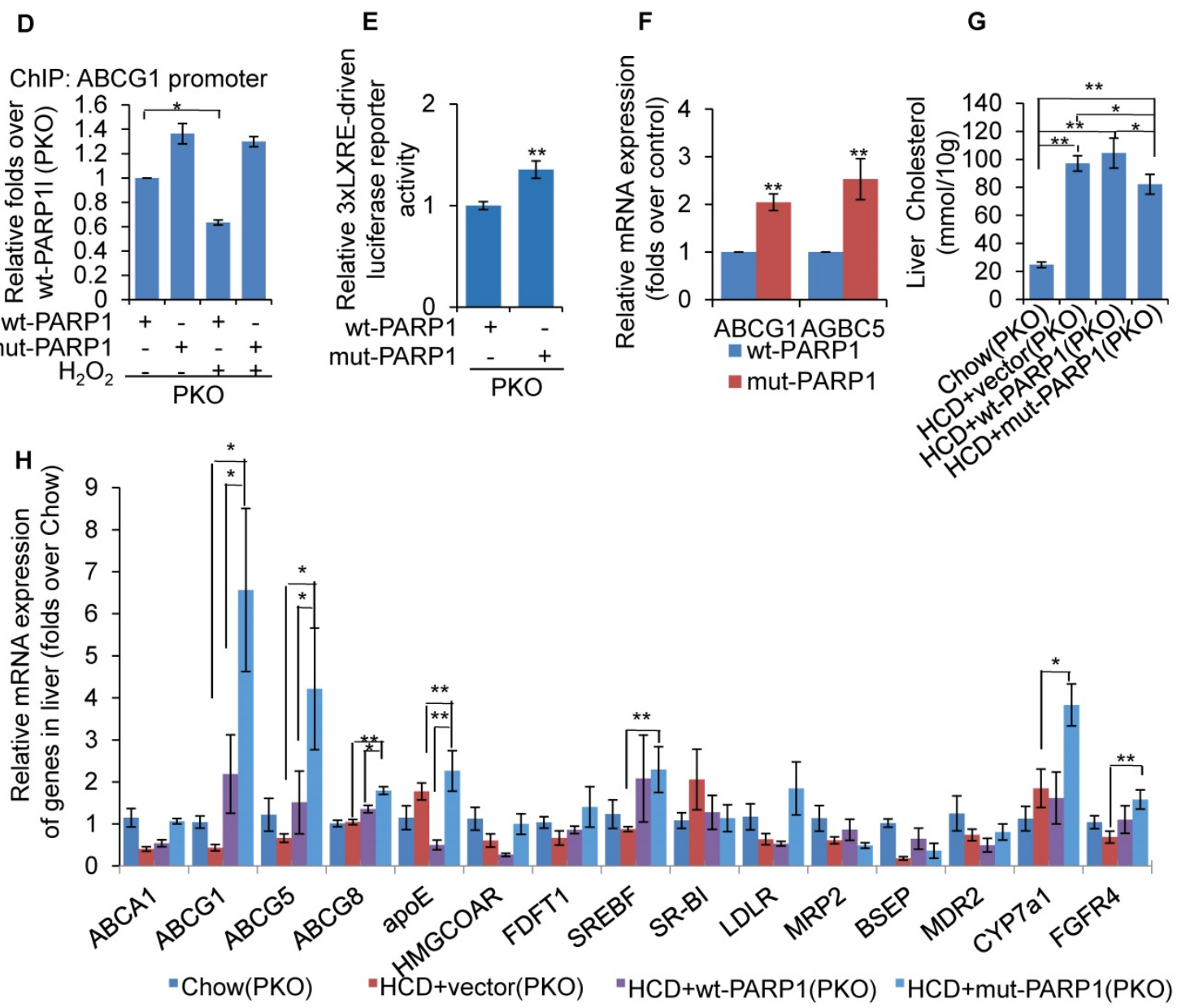

Figure 5. Unactivated (un-poly(ADP-ribosyl)ated) PARP1 promoted LXRa transactivation. (A) Nuclear extracts from hepatocytes from WT mice were incubated with anti-LXRa antibody, anti-PARPI antibody or non-specific IgG (negative control), then analyzed by supershift assay ( $\mathrm{n}=3$ ). (B) re-ChIP assays, in which chromatin was first immunoprecipitated with anti-LXRa antibody then re-immunoprecipitated with anti-PARPI antibody, or anti-PAR antibody ( $\mathrm{n}=3$ ). (C) Co-immunoprecipitation (Co-IP) of PARPI-bound proteins from hepatocytes of PKO mice, followed by Western blot analysis using anti-LXRa antibody. After transfection with full-length (wt-PARPI, 48h) or mutant (mut-PARPI, 48h) vectors, cells were treated with vehicle (PBS) or $\mathrm{H}_{2} \mathrm{O}_{2}(0.3 \mathrm{mM}, 0.5 \mathrm{~h})$. ( $\mathrm{n}=3$ ). Data are expressed as mean \pm SEM, ${ }^{*} \mathrm{P}<0.05$. (D) $\mathrm{ChIP-PCR}$ assay using anti-LXRa antibody for amplification of ABCG1 promoters in hepatocytes from PKO mice. Cells were transfected with a full-length (wt-PARP1) or mutant (mut-PARP1) vector for 48 hours $(n=3)$. Data are expressed as mean $\pm S E M, * P<0.05$. (E) mRNA expression of selected genes in hepatocytes from PKO mice transfected with a full-length (wt-PARP1) or mutant (mut-PARP1) vector for 48 hours $(n=3)$. Data are expressed as mean \pm SEM. $* * P<0.01$ vs wt-PARPI group. In $\mathrm{G}-\mathrm{H}, \mathrm{PKO}$ mice were fed a SCD $(C$ how, $n=5)$ or $\mathrm{HCD}$ transfected with empty $(n=5)$, full-length (wt-PARPI, $n=5$ ) or mutant (mut-PARPI, $n=5)$ vector. $(G)$ Cholesterol concentration in the livers of PKO mice. $(H)$ mRNA expression of selected genes in PKO mice. In G-H, data are expressed as mean \pm SEM, $* P<0.05, * * P<0.01$.

\section{Un-poly(ADP-ribosyl)ated PARP 1 promoted LXR $\alpha$ transactivation}

As PARP1 is required for recruitment of LXRa to the target promoter, we suspected that it might be an important component of LXRa-LXRE complex. As shown in Figure 5A, incubation with anti-PARP1 antibody shifted the LXRa-LXRE complex band, indicating that PARP1 is indeed an essential component of the LXRa-LXRE complex. This finding was further confirmed by the results of the re-ChIP (ChIP on ChIP) assay, which revealed that PARP1 bound to ABCG1 promoter associated with LXRa (Figure 5B). Furthermore, the poly(ADP-ribosyl)ated protein could not bind to LXRE (Figure 5B), this indicated un-poly(ADP-ribosyl)ated, rather than activated, PARP1 was is required for the binding of LXRa to the ABCG1 promoter. 
To further support this finding, the effects of mut-PARP1 and wt-PARP1 on the binding of LXRa to the ABCG1 promoter were investigated. Although lack of enzymatic activity did not alter the association between PARP1 and LXRa, forced expression of mut-PARP1 relative to wt-PARP1 resulted in clearly increased binding of LXRa to the ABCG1 promoter (Figures 5C and 5D). Moreover, treatment with $\mathrm{H} 2 \mathrm{O} 2$ suppressed the wt-PARP1-induced, not mut-PARP1-induced, promoter binding of LXRa (Figure 5D). Taken together, these results indicate that unactivated/un-poly(ADP-ribosyl)ated PARP1 is a prerequisite for recruitment of LXRa to target promoter. Consistent with this, forced expression of mut-PARP1 resulted in higher luciferase activity driven by $3 \times$ LXRE than did wt-PARP1 transfection (Figure 5E), suggesting that unactivated PARP1 increased LXRa transactivity. Consistent with this finding, forced expression of mut-PARP1 relative to wt-PARP1 resulted in higher expression of the LXRa targets ABCG1 and ABCG5 in PKO cells (Figure 5F). Taken together, the results suggest that unactivated PARP1 promotes LXRa binding to its target promoter to increase gene transcription. Besides, forced expression of mut-PARP1 relative to wt-PARP1 or in cells transfected with empty vectors resulted in decreased cholesterol accumulation and enhanced hepatic expression of LXRa target genes involved in cholesterol disposal (Figures 5G \& 5H). All these suggested that forced expression of mut-PARP1 might alleviate cholesterol accumulation through activation of LXRa signaling.

\section{Inhibition of PARP 1-mediated ligand-induced LXR $\alpha$ transactivation}

LXRa can be activated by endogenous oxysterols or the synthetic ligands GW3965 and T0901317. To determine whether PARP1 is involved in ligand-induced LXRa activation, PARP1 was knocked down using siRNA in HepG2 cells. As shown in Figure 6A, PARP1 knockdown abolished the recruitment of GW3965-induced LXRa to the ABCG1 promoter (Figure 6A). Consistent with this, knockdown of PARP1 also abrogated the GW3965induced increase in 3xLXRE driven luciferase activity (Figure 6B). Taken together, PARP1 is a prerequisite for ligand-induced LXRa binding to its target promoter and transactivation.

In this study, activated PARP1 was shown to suppress LXRa transactivation through poly(ADPribosy)lation. We thus suspected that ligand-induced LXRa target expression might also be suppressed upon PARP1 activation. This hypothesis was confirmed by the observation that $\mathrm{H}_{2} \mathrm{O}_{2}$ treatment effectively suppressed GW3965-induced expression of
ABCA1, ABCG1 and ABCG5 in HepG2 cells (Figure 6C). Consistent with this, GW3965-induced binding of LXRa to the ABCG1 promoter and increased 3xLXRE driven luciferase activity were also suppressed by $\mathrm{H}_{2} \mathrm{O}_{2}$ treatment (Figures 6D \& 6E).

Given that GW3965-induced LXRa transactivation could be suppressed by $\mathrm{H}_{2} \mathrm{O}_{2}$, together with the observation that PARP1 is a requirement for GW3965-induced LXRa transactivation, we suspected that these LXRa ligands might also suppress cellular PARP1 activity. HepG2 cells were treated with GW3965, T0901317 and 22(R)-HC, and the whole extracts were subjected to PARP activity assay and Western blot analysis. As shown in Figures 6F, 6G, 7A and 7B, administration of GW3965, T0901317 or 22(R)-HC reduced PARP activity and total protein poly(ADP-ribosy)lation levels in a dosage-dependent manner, indicating that cellular PARP activities were indeed suppressed.

In agreement with this, administration of GW3965 effectively suppressed poly(ADP-ribosy)lation of PARP1 (Figure 6H), indicating that GW3965 suppressed PARP1 activation. Accordingly, the poly(ADP-ribosy)lation of LXRa decreased significantly following GW3965 treatment (Figure 6I). Similar results were achieved when cells were treated with either T0901317 or 22(R)-HC (Figures 7C \& 7D).

\section{Discussion}

In this study, we revealed that activation of PARP1 promoted hepatic cholesterol accumulation through the impairment of LXRa signaling in liver when fed a HCD. Moreover, we identified LXRa as a substrate of the PARP1-mediated poly(ADP-ribosyl)ation reaction. Poly(ADP-ribosyl)ation prevents LXRa associating with its cognate target sequence (LXRE) in promoters, and thus suppresses gene transcription. Intriguingly, we found that unactivated PARP1 is an essential component of the LXRa-LXRE complex. Its deficiency inhibits LXRa binding to the target promoter, and thus suppresses gene transcription.

Long-term intracellular accumulation of free cholesterol in the liver can result in the formation of cholesterol crystals, potentially triggering liver inflammation [33]. Therefore, liver cholesterol is regarded as a substantial risk factor for the development of non-alcoholic steatohepatitis (NASH) [34]. As cholesterol homeostasis is maintained by the balance between cholesterol availability (intake and de novo synthesis) and disposal (catabolism and secretion), impaired LXRa signaling and resultant insufficiency of cholesterol disposal should inevitably lead to cholesterol over-accumulation, especially when challenged with high dietary cholesterol. In this study, suppression of PARP1 activation alleviates 
cholesterol accumulation by facilitating cholesterol disposal, indicating that PARP1-induced impairment of LXRa sensing is an important mechanism underlying liver cholesterol metabolic disorders, including NASH [20].

Poly(ADP-ribosyl)ation is an important posttranslational modification of proteins. It is common for poly(ADP-ribosyl)ation to exert two contrary effects on the DNA-binding capacity of its acceptor proteins: suppression or promotion. The suppressive effects of protein-DNA interactions are usually attributed to the addition of negatively charged ADPribose polymer to acceptor proteins, resulting in a repulsion of the negative charges on the poly(ADPribosyl)ated modified proteins and DNA strands. Conversely, poly(ADP-ribosyl)ation can also increase the DNA binding capacity of many specific acceptor proteins, such as c-Jun and c-fos in the nucleus. This effect is generally mediated by the formation of a DNA-binding scaffold on the acceptor proteins, which increases the DNA binding capability of the acceptor proteins [20, 35]. In this study, we found that poly(ADP-ribosyl)ation decreased the DNA binding activity of LXRa to LXRE, leading to decreased target gene transcription. Actually, we and others have previously demonstrated that poly(ADP-ribosyl)ation increases the DNA binding capacity of ERa, but decreases the capacity of PPARY and PPARa $[18,19$, 36]. All these findings indicate that PARP1-mediated poly(ADP-ribosyl)ation is an important mechanism regulating the promoter binding and transactivity of many nuclear acceptors.
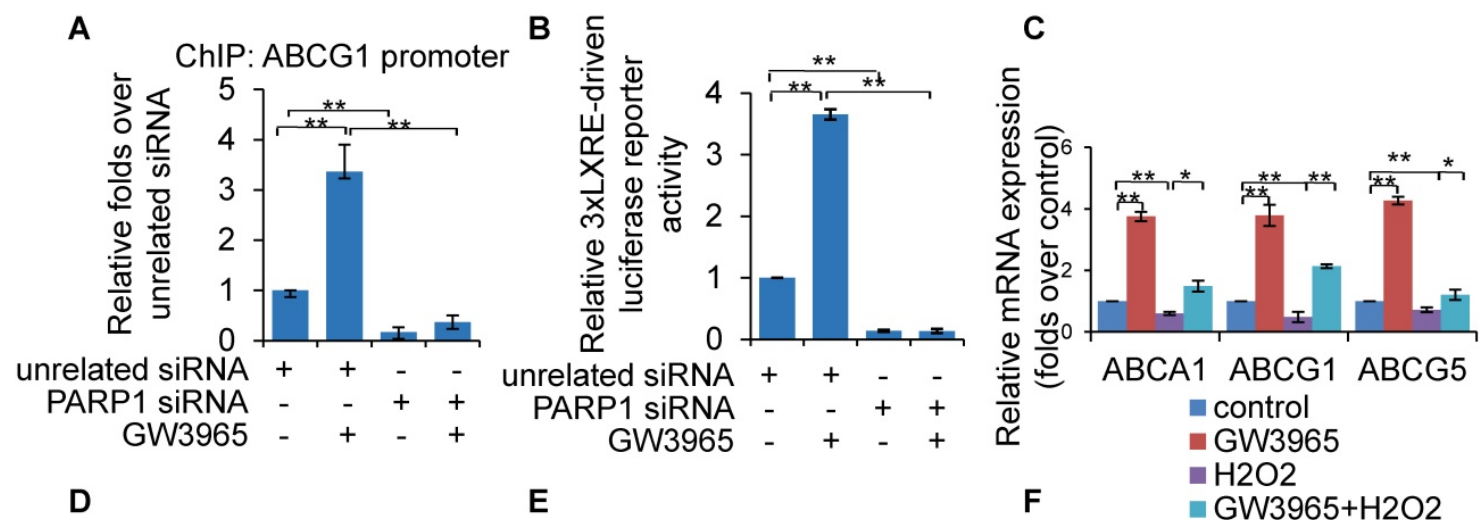

D

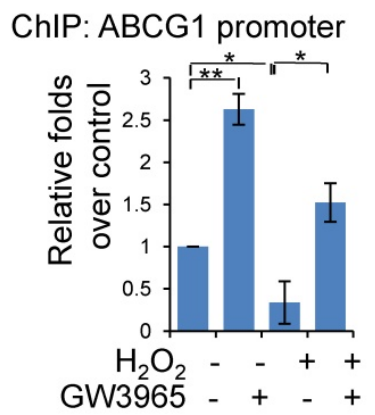

G

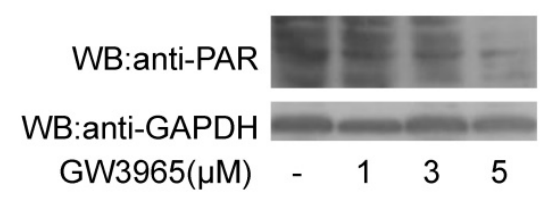

E

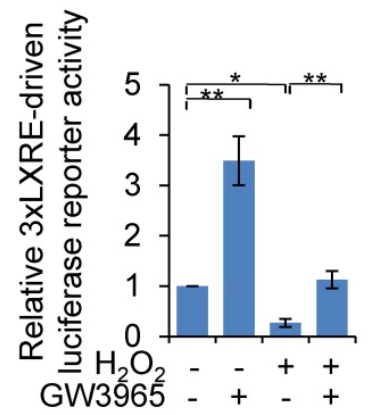

H

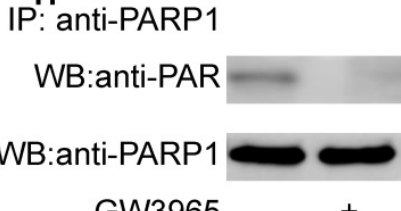

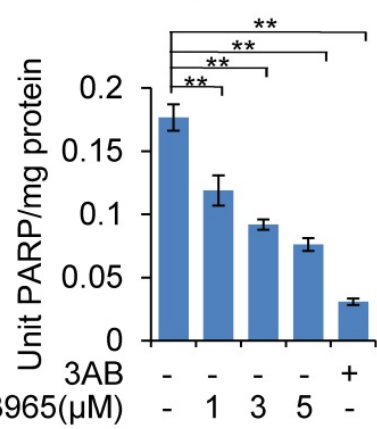

$\mathrm{GW} 3965(\mu \mathrm{M})-135-$

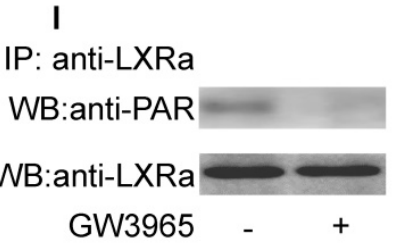

Figure 6. Inhibition of PARPI mediated ligand-induced LXRa transactivation. Ligands included GW3965, T0901317 and 22(R)-hydroxycholesterol,. (A) ChIP-PCR assay using anti-LXRa antibody for amplification of ABCG1 promoters in HepG2 cells. Cells were treated with PARP1 siRNA ( $50 \mathrm{nM}, 48 \mathrm{~h}$ ) or unrelated siRNA ( $50 \mathrm{nM}, 48 \mathrm{~h}$ ) in the absence or presence of GW3965 (1 $\mu \mathrm{M}, 24 \mathrm{~h})(\mathrm{n}=3)$. (B) Relative LXRE-driven luciferase activity in HepG2 cells. Cells were treated with PARP1 siRNA (50 nM, $48 \mathrm{~h})$ or unrelated siRNA $(50 \mathrm{nM}, 48 \mathrm{~h})$ in the absence or presence of GW3965 (1 $\mu \mathrm{M}, 24 \mathrm{~h})(\mathrm{n}=3)$. (C) mRNA expression of selected genes in HepG2 cells treated with vehicle $(\mathrm{PBS})$ or $\mathrm{H}_{2} \mathrm{O}_{2}(0.3 \mathrm{mM}, 0.5 \mathrm{~h})$ in the absence or presence of GW3965 (1 $\mu \mathrm{M}, 24 \mathrm{~h})(\mathrm{n}=3)$. (D) ChIP-PCR assay using anti-LXRa antibody for amplification of ABCG1 promoters in HepG2 cells treated with vehicle (PBS) or $\mathrm{H}_{2} \mathrm{O}_{2}(0.3 \mathrm{mM}, 0.5 \mathrm{~h})$ in the absence or presence of GW3965 $(1 \mu \mathrm{M}, 24 \mathrm{~h})(\mathrm{n}=3)$. (E) Relative LXRE-driven luciferase activity in HepG2 cells. Cells were treated with vehicle (PBS) or $\mathrm{H}_{2} \mathrm{O}_{2}(0.3 \mathrm{mM}, 0.5 \mathrm{~h})$ in the absence or presence of GW3965 (1 $\left.\mu \mathrm{M}, 24 \mathrm{~h}\right)(\mathrm{n}=3)$. (F) PARP activity in HepG2 cells. Cells were treated with GW3965 (1, 3 , $5 \mu \mathrm{M})$, for 24 hours. $3 A B(10 \mathrm{mM})$ was used as positive control $(n=3)$. $(\mathrm{G})$ Western blot assay of poly(ADP-ribosyl)ated proteins and PARP1 in whole extracts of HepG2 cells treated with vehicle (DMSO) or GW3965 $(1,3,5 \mu \mathrm{M})(\mathrm{n}=3)$. (H) Poly(ADP-ribosy)lation of PARP1 in HepG2 cells determined by IP with PARP1 followed by Western blot analysis using anti-PAR antibody. Western blotting with anti-PARPI served as the loading control. Cells were treated with vehicle (DMSO) or GW3965 (1 $\mu$ M, 24h) ( $\mathrm{n}=3$ ). (I) Poly(ADP-ribosyl)ation levels of LXRa in whole extracts of HepG2 cells determined by IP with LXRa followed by Western blot analysis using anti-PAR antibody. Western-blotting with anti-LXRa antibody served as the loading control. Cells were treated with vehicle (DMSO) or GW3965 (1 $\mu M, 24 \mathrm{~h})(\mathrm{n}=3)$. In A-F, data are expressed as mean \pm SEM, $* P<0.05, * * P<0.01$. 

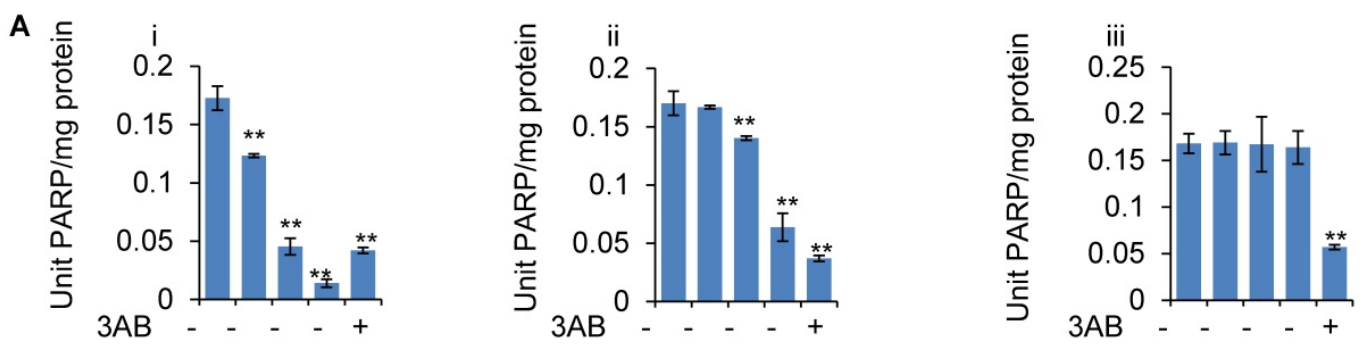

$\mathrm{T} 09013171(\mu \mathrm{M})-135-22(\mathrm{R})-\mathrm{HC}(\mu \mathrm{M})-0.513-$

nicotinic acid $(\mu M)-1510-$

B

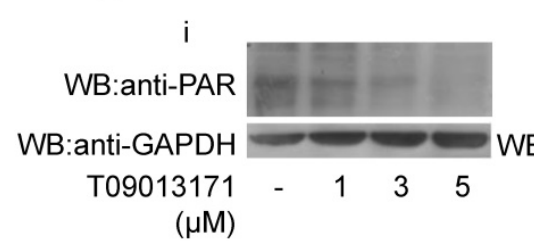

$(\mu \mathrm{M})$

C

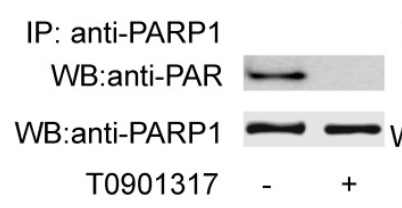

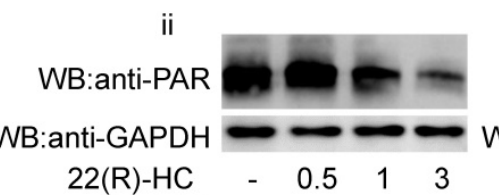

$(\mu \mathrm{M})$

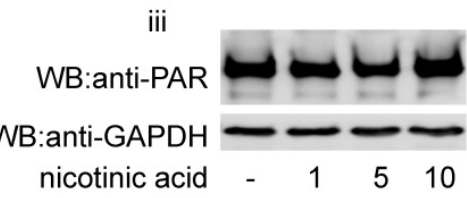

$(\mu \mathrm{M})$

D
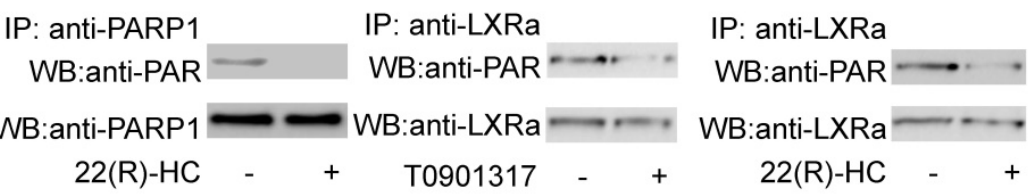

Figure 7. Role of T0901317 and 22(R)-HC on PARP activity. (A) mRNA expression of selected genes in HepG2 cells treated with PARP1 siRNA (50 nM, 48h) or unrelated siRNA $(50 \mathrm{nM}, 48 \mathrm{~h})$ in the absence or presence of T0901317 $(1 \mu \mathrm{M}, 24 \mathrm{~h})$ or $22(\mathrm{R})-\mathrm{HC}(1 \mu \mathrm{M}, 24 \mathrm{~h})(\mathrm{n}=3)$. Data are expressed as mean \pm SEM, ${ }^{*} \mathrm{P}<0.05$, ** $\mathrm{P}<0.01$. (B) Western blot assay of poly(ADP-ribosyl)ated proteins in whole extracts of HepG2 cells treated with: (i) T0901317 (1, 3, $5 \mu \mathrm{M}$ ); (ii) 22(R)-hydroxycholesterol (0.5, 1, $3 \mu \mathrm{M})$ or (iii) nicotinic acid $(1,5,10 \mu M)$ for 24 hours $(n=3)$. (C) Poly(ADP-ribosy)lation of PARP1 in HepG2 cells determined by IP with PARPI followed by Western blot analysis using anti-PAR antibody. Western-blotting with anti-PARPI served as the loading control. Cells were treated with vehicle (DMSO), T0901317 (1 $\mu$ M, $24 \mathrm{~h})$ or $22(\mathrm{R})$-HC $(1 \mu \mathrm{M}, 24 \mathrm{~h})(\mathrm{n}=3)$. (D) Poly(ADP-ribosyl)ation levels of LXRa in whole extracts of HepG2 cells determined by IP with LXRa followed by Western blot analysis using anti-PAR antibody. Western-blotting with anti-LXRa antibody served as the loading control. Cells were treated with vehicle (DMSO), T0901317 (1 $\mu M, 24 \mathrm{~h})$ or 22(R)-HC (1 $\mu$ M, 24h) ( $\mathrm{n}=3$ ).

In the nucleus, LXRa can be activated by various ligands and synthetic agonists. Surprisingly, we found that inhibition of PARP1 activity mediates ligand-induced LXRa activation, including induction by GW3965, T0901317 and 22(R)-HC. From this finding it is rational to expect that an association with unactivated PARP1 is required for LXRa binding to the target promoter, either in the absence or presence of ligands. Moreover, although it is unknown whether this finding can be extended to all LXRa ligands, it at least suggests that inhibition of PARP1 activity might represent a novel strategy for the design of LXRa ligands/activators in the future.

In the present study, a very interesting finding is that, although PARP1 suppresses LXRa signaling through poly(ADP-ribosyl)ation, PARP1 per se is indispensable for LXRa transactivation and target expression. This is due to the essential role of unactivated PARP1 in the binding of LXRa to its target promoter, i.e. un-activated PARP1 is a transcriptional co-activator of LXRa. Indeed, the fact that PARP1 functions as a co-factor for transcription factors has been reported by many studies, e.g. Hassa et al. report that PARP1 is an important transcriptional co-factor of NF-kB, which promotes
NF-KB transactivation through physical interaction [37]. Interestingly, they also found that the enzymatic activity of PARP1 is unnecessary for its function as a transcriptional cofactor. However, in many conditions, poly(ADP-ribosyl)ation is an important mechanism regulating protein-protein interactions since it changes the structure of acceptor proteins by adding nucleic acid-like (poly(ADP-ribose)) polymer or forming a PAR-scaffold structure [38]. However, according to our results, even though LXRa can bind to and interact with activated PARP1, and this binding inhibits target gene transcription.

The mechanism underlying the regulation of LXRa signaling is very complex and remains unclear to a large extent. A model has been proposed to describe the activation of LXRa in the nucleus: unligated LXRa binds to cognate LXREs and inhibits transcription by recruiting nuclear co-repressors. Ligand binding first results in dissociation of corepressor and moderate activation of transcription. This then elicits recruitment of a co-activator, thus causing maximal activation of transcription [3, 39]. However, our data revealed that, in the absence of ligands, some parts of LXRa are poly(ADP-ribosyl)ated by PARP1, which in turn, prevents recruitment 
to the target promoter. In this condition, LXRa signaling has not been activated. When ligands are present in the nucleus, PARP1 activity is suppressed, leading to increased nuclear content of unactivated PARP1 and un-poly(ADP-ribosyl)ated LXRa, which associate with each other and thereafter become recruited to the target promoters to facilitate gene transcription. This model takes the following findings into consideration: (1) LXRa can be poly(ADPribosyl)ated by PARP1 and poly(ADP-ribosyl)ation inhibits LXRa-promoter complex formation; (2) direct interaction with unactivated PARP1 is a prerequisite for the recruitment of LXRa to its target promoter; (3) LXRa ligands are PARP1 inhibitors and PARP1 is a prerequisite for ligand-induced LXRa transactivation. This model emphasizes the essential role of PARP1 in the regulation of the LXRa signaling pathway.

\section{Conclusions}

Our study has revealed an important contribution of PARP1-mediation to the suppression of the LXRa signaling pathway in the pathogenesis of HCD-induced hepatic cholesterol over-accumulation. Furthermore, we have identified PARP1 as a key regulator of the LXRa signaling pathway, with inhibition of PARP1 activity mediating ligandinduced LXRa activation. These findings imply that PARP1 could be a potential target in the development of drugs and therapeutic strategies for the treatment of hepatic cholesterol metabolism disorders induced by impaired LXRa signaling.

\section{Abbreviations}

HCD, high cholesterol diet; KO, knockout; LXRa, Liver $X$ receptor $a$; LXREs, LXR response elements; NRs, Nuclear receptors; PARP1, Poly(ADP-ribose) polymerase 1 ; RXR, retinoid $\mathrm{X}$ receptor; WT: Wildtype.

\section{Supplementary Material}

Supplementary figure S1.

http://www.ijbs.com/v16p2868s1.pdf

\section{Acknowledgements}

We thank Dr. David J. Mangelsdorf, Dr. Steven L. Sabol, Dr. Yun Zhang and Dr. Yoshinari Uehara for kindly providing plasmids. We also thank help from Dr. Youming Lu (Louisiana State University Health Science Center, New Orleans) and Dr. Weiping Zou (Surgery, Immunology and Biology and Director for Translational Research, University of Michigan).

\section{Funding}

This work was supported by National Natural Science Foundation of China (30971245 to Kai Huang,
81670241 to Dan Huang and 81400303 to Fengxiao Zhang).

\section{Author Contributions}

CW, YHJ, FXZ, and Kai Huang conceived and designed the study; FXZ, YHJ, CW, XL, MD, DH and Kun Huang performed the experiments and analyzed data; FXZ, DH and Kai Huang wrote the manuscript. All authors read and approved the final manuscript.

\section{Competing Interests}

The authors have declared that no competing interest exists.

\section{References}

1. McKenna NJ, Lanz RB, O'Malley BW. Nuclear receptor coregulators: cellular and molecular biology. Endocr Rev. 1999; 20: 321-44.

2. Bischoff ED, Daige CL, Petrowski M, Dedman H, Pattison J, Juliano J, et al. Non-redundant roles for LXRalpha and LXRbeta in atherosclerosis susceptibility in low density lipoprotein receptor knockout mice. J Lipid Res. 2010; 51: 900-6.

3. Wojcicka G, Jamroz-Wisniewska A, Horoszewicz K, Beltowski J. Liver X receptors (LXRs). Part I: structure, function, regulation of activity, and role in lipid metabolism. Postepy Hig Med Dosw (Online). 2007; 61: 736-59.

4. Geyeregger R, Zeyda M, Stulnig TM. Liver $X$ receptors in cardiovascular and metabolic disease. Cell Mol Life Sci. 2006; 63: 524-39.

5. Willy PJ, Umesono K, Ong ES, Evans RM, Heyman RA, Mangelsdorf DJ. LXR, a nuclear receptor that defines a distinct retinoid response pathway. Genes Dev. 1995; 9: 1033-45.

6. Krasowski MD, Ni A, Hagey LR, Ekins S. Evolution of promiscuous nuclear hormone receptors: LXR, FXR, VDR, PXR, and CAR. Mol Cell Endocrinol. 2011; 334: 39-48.

7. Ory DS. Nuclear receptor signaling in the control of cholesterol homeostasis: have the orphans found a home? Circ Res. 2004; 95: 660-70.

8. Desvergne B, Michalik L, Wahli W. Transcriptional regulation of metabolism. Physiol Rev. 2006; 86: 465-514.

9. Makishima M. Nuclear receptors as targets for drug development: regulation of cholesterol and bile acid metabolism by nuclear receptors. J Pharmacol Sci. 2005; 97: 177-83.

10. Edwards PA, Kennedy MA, Mak PA. LXRs; oxysterol-activated nuclear receptors that regulate genes controlling lipid homeostasis. Vascul Pharmacol. 2002; 38: 249-56.

11. Jakobsson T, Treuter E, Gustafsson JA, Steffensen KR. Liver X receptor biology and pharmacology: new pathways, challenges and opportunities. Trends in pharmacological sciences. 2012; 33: 394-404.

12. Kraus WL. Transcriptional control by PARP-1: chromatin modulation, enhancer-binding, coregulation, and insulation. Current opinion in cell biology. 2008; 20: 294-302.

13. Kraus WL, Lis JT. PARP goes transcription. Cell. 2003; 113: 677-83.

14. Luo $X$, Kraus WL. On PAR with PARP: cellular stress signaling through poly(ADP-ribose) and PARP-1. Genes Dev. 2012; 26: 417-32.

15. de Murcia JM, Niedergang C, Trucco C, Ricoul M, Dutrillaux B, Mark M, et al. Requirement of poly(ADP-ribose) polymerase in recovery from DNA damage in mice and in cells. Proc Natl Acad Sci U S A. 1997; 94: 7303-7.

16. Kim MY, Zhang T, Kraus WL. Poly(ADP-ribosyl)ation by PARP-1: 'PAR-laying' NAD+ into a nuclear signal. Genes Dev. 2005; 19: 1951-67.

17. Wang C, Zhang F, Wang L, Zhang Y, Li X, Huang K, et al. Poly(ADP-ribose) polymerase 1 promotes oxidative-stress-induced liver cell death via suppressing farnesoid $X$ receptor alpha. Mol Cell Biol. 2013; 33: 4492-503.

18. Huang D, Yang C, Wang $Y$, Liao $Y$, Huang K. PARP-1 suppresses adiponectin expression through poly(ADP-ribosyl)ation of PPAR gamma in cardiac fibroblasts. Cardiovasc Res. 2009; 81: 98-107.

19. Zhang F, Wang $Y$, Wang L, Luo X, Huang K, Wang C, et al. Poly(ADP-ribose) polymerase 1 is a key regulator of estrogen receptor alpha-dependent gene transcription. The Journal of biological chemistry. 2013; 288: 11348-57.

20. Huang D, Wang Y, Yang C, Liao Y, Huang K. Angiotensin II promotes poly(ADP-ribosyl)ation of c-Jun/c-Fos in cardiac fibroblasts. J Mol Cell Cardiol. 2009; 46: 25-32.

21. von Lukowicz T, Hassa PO, Lohmann C, Boren J, Braunersreuther V, Mach F, et al. PARP1 is required for adhesion molecule expression in atherogenesis. Cardiovasc Res. 2008; 78: 158-66.

22. Huang K, Du M, Tan X, Yang L, Li X, Jiang Y, et al. PARP1-mediated PPARalpha poly(ADP-ribosyl)ation suppresses fatty acid oxidation in non-alcoholic fatty liver disease. Journal of hepatology. 2017; 66: 962-77.

23. Ito S, Fujimori T, Furuya A, Satoh J, Nabeshima Y, Nabeshima Y. Impaired negative feedback suppression of bile acid synthesis in mice lacking betaKlotho. The Journal of clinical investigation. 2005; 115: 2202-8. 
24. Matsuoka T, Ueda S, Matsumoto H, Kawakami M. An ultrasensitive enzymatic method for measuring mevalonic acid in serum. Journal of lipid research. 2012; 53: 1987-92.

25. Kindt E, Szekely-Klepser G, Fountain ST. The validation of a simple LC/MS/MS method for determining the level of mevalonic acid in human plasma. Biomedical chromatography : BMC. 2011; 25: 323-9.

26. Neufeld DS. Isolation of rat liver hepatocytes. Methods Mol Biol. 1997; 75: 145-51.

27. Pawar A, Xu J, Jerks E, Mangelsdorf DJ, Jump DB. Fatty acid regulation of liver $\mathrm{X}$ receptors $(\mathrm{LXR})$ and peroxisome proliferator-activated receptor alpha (PPARalpha ) in HEK293 cells. J Biol Chem. 2002; 277: 39243-50.

28. Uehara Y, Miura S, von Eckardstein A, Abe S, Fujii A, Matsuo Y, et al. Unsaturated fatty acids suppress the expression of the ATP-binding cassette transporter G1 (ABCG1) and ABCA1 genes via an LXR/RXR responsive element. Atherosclerosis. 2007; 191: 11-21.

29. Wang C, Zhang F, Wang L, Zhang Y, Li X, Huang K, et al. Poly(ADP-ribose) polymerase 1 promotes oxidative-stress-induced liver cell death via suppressing farnesoid $X$ receptor alpha. Mol Cell Biol. 33: 4492-503.

30. Schmiesing JA, Ball AR, Jr., Gregson HC, Alderton JM, Zhou S, Yokomori K. Identification of two distinct human SMC protein complexes involved in mitotic chromosome dynamics. Proc Natl Acad Sci U S A. 1998; 95: 12906-11.

31. Peet DJ, Turley SD, Ma W, Janowski BA, Lobaccaro JM, Hammer RE, et al. Cholesterol and bile acid metabolism are impaired in mice lacking the nuclear oxysterol receptor LXR alpha. Cell. 1998; 93: 693-704.

32. Sumiyoshi M, Sakanaka M, Kimura Y. Chronic intake of a high-cholesterol diet resulted in hepatic steatosis, focal nodular hyperplasia and fibrosis in non-obese mice. The British journal of nutrition. 2010; 103: 378-85.

33. Walenbergh SM, Shiri-Sverdlov R. Cholesterol is a significant risk factor for non-alcoholic steatohepatitis. Expert Rev Gastroenterol Hepatol. 2015; 9: 1343-6.

34. Van Rooyen DM, Larter CZ, Haigh WG, Yeh MM, Ioannou G, Kuver R, et al. Hepatic free cholesterol accumulates in obese, diabetic mice and causes nonalcoholic steatohepatitis. Gastroenterology. 2011; 141: 1393-403, 403 e1-5.

35. Rouleau M, Patel A, Hendzel MJ, Kaufmann SH, Poirier GG. PARP inhibition: PARP1 and beyond. Nature reviews Cancer. 2010; 10: 293-301.

36. Huang K, Du M, Tan X, Yang L, Li X, Jiang Y, et al. PARP1-mediated PPARalpha poly(ADP-ribosyl)ation suppresses fatty acid oxidation in non-alcoholic fatty liver disease. Journal of hepatology. 2016.

37. Hassa PO, Covic M, Hasan S, Imhof R, Hottiger MO. The Enzymatic and DNA Binding Activity of PARP-1 Are Not Required for NF- $\mathrm{KB}$ Coactivator Function. Journal of Biological Chemistry. 2001; 276: 45588-97.

38. Gibson BA, Kraus WL. New insights into the molecular and cellular functions of poly(ADP-ribose) and PARPs. Nature reviews Molecular cell biology. 2012; 13: 411-24.

39. Zelcer $\mathrm{N}$, Tontonoz $\mathrm{P}$. Liver $\mathrm{X}$ receptors as integrators of metabolic and inflammatory signaling. The Journal of clinical investigation. 2006; 116: 607-14. 